\title{
Interface Reactions Responsible for Run-Out in Active Brazing: Part 1
}

\author{
This study aimed to understand the fundamental principles of run-out by examining \\ the interface reaction between $\mathrm{Ag}$-XAl filler metals and Kovar ${ }^{\mathrm{TM}}$ base material
}

\author{
BY P. T. VIANCO, C. A. WALKER, D. DE SMET, A. KILGO, B. M. McKENZIE, AND R. L. GRANT
}

\begin{abstract}
The run-out phenomenon was observed in Ag-Cu-Zr active braze joints made between the alumina ceramic and KovarTM base material. Run-out introduces a significant yield loss by generating functional and/or cosmetic defects in brazements. A prior study identified a correlation between run-out and the aluminum (Al) released by the reduction/oxidation reaction with alumina and aluminum's reaction with the KovarTM base material. A study was undertaken to understand the fundamental principles of run-out by examining the interface reaction between Ag-xAl filler metals ( $x=2,5$, and $10 \mathrm{wt}-\%$ ) and KovarTM base material. Sessile drop samples were fabricated using brazing temperatures of $965^{\circ}\left(1769^{\circ} \mathrm{F}\right)$ or $995^{\circ} \mathrm{C}\left(1823^{\circ} \mathrm{F}\right)$ and times of 5 or $20 \mathrm{~min}$. The correlation was made between the degree of wetting and spreading by the sessile drops and the run-out phenomenon. Wetting and spreading increased with $\mathrm{Al}$ content $(\mathrm{x})$ of the Ag-xAl filler metal, but was largely insensitive to the brazing process parameters. The increased $\mathrm{Al}$ concentration resulted in higher $\mathrm{Al}$ contents of the (Fe, $\mathrm{Ni}, \mathrm{Co})_{x} \mathrm{Al}_{\mathrm{y}}$ reaction layer. Run-out was predicted when the filler metal has a locally elevated Al content exceeding 2-5 wt-\%. Several mitigation strategies were proposed, based upon these findings.
\end{abstract}

\section{KEYWORDS}

- Active Braze • Run-Out • Interface Reactions • Sessile Drop Samples

\section{Introduction}

\section{Run-Out in Ag-Cu-Zr Active Braze Joints}

Braze joints exhibit optimum processibility as well as long-term reliability when the amount of filler metal is controlled in the gap. Too little filler metal results in voids that compromise strength and hermeticity. Excess filler metal flows out of the gap where it collects on exterior surfaces as one form of run-out. Beside causing unsightly cosmetic defects, run-out material can im- pede visual and $x$-ray inspections, interfere with next-assembly fitup or mechanical actuations, and generate excessive residual stresses that lead to cracks in the base material.

A second form of run-out occurs in active braze joints. This phenomenon was observed during development of the 97Ag-1Cu-2Zr filler metal (wt-\%, abbreviated $\mathrm{Ag}-\mathrm{Cu}-\mathrm{Zr}$ ) for joining $\mathrm{Al}_{2} \mathrm{O}_{3}$ ceramic (alumina) to the Kovar ${ }^{\mathrm{TM}}$ base material (Refs. 1, 2). As illustrated in Fig. 1, there is a localized area where a filler metal "lobe" wets and spreads on the $\operatorname{Kovar}^{\mathrm{TM}}$ spacer well beyond the im- mediate joint footprint. The scanning electron microscope (SEM) photograph in Fig. 2 shows a metallographic cross section of the run-out lobe. The run-out behavior was confirmed to not be caused by excessive filler metal. ${ }^{1}$ The following section briefly summarizes the important findings from an earlier study of this behavior.

\section{Important Findings from the Alumina/Ag-Cu-Zr/KovarTM Application}

\section{Reaction Layers}

The test specimen shown in Fig. 1 was used to assess run-out in the alumina/Ag-Cu-Zr/Kovar ${ }^{\mathrm{TM}}$ application (Ref. 3). A photograph shows the entire specimen in Fig. 3. The base materials were the two alumina buttons and the Kovar $^{\mathrm{TM}}$ spacer. The spacer had 0.038-mm (0.0015-in.) dimples that controlled the joint clearance. The Ag-Cu-Zr filler metal was fabricated into an annular ring having a footprint that matched the dimensions of the alumina faying surfaces: 10.2-mm (0.400-in.) inner diameter (ID) and 15.8-mm (0.625-in.) outer diameter (OD). The Ag-Cu-Zr preform was $0.051 \mathrm{~mm}$ (0.002 in.) thick. The two varieties of alumina ceramics, which were distinguishable by different colors, exhibited similar run-out behaviors.

\section{Footnote:}

1. The groove in the KovarTM spacer was placed there to prevent the run-out behavior; it was not successful at doing so. 


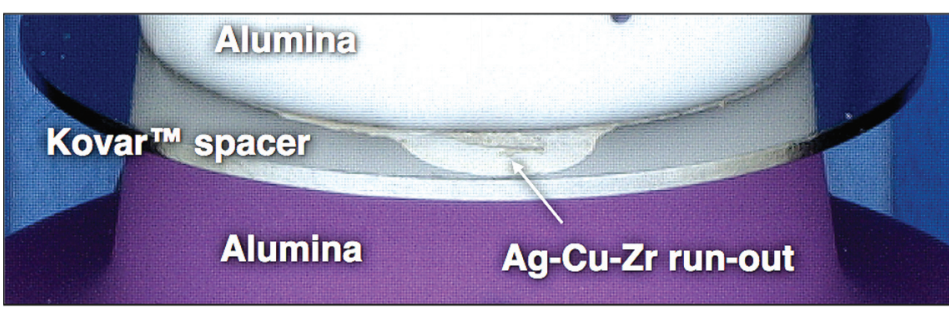

Fig. 1 - Photograph shows run-out by the Ag-Cu-Zr active braze alloy used to join alumina parts to the KovarTM spacer.

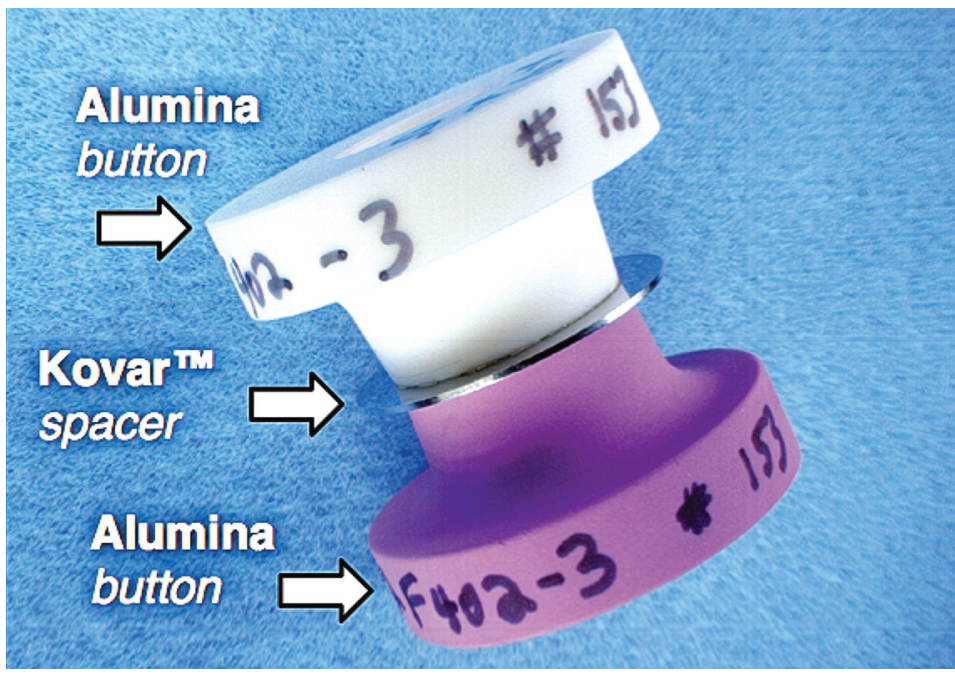

Fig. 3 - Photograph shows the tensile test sample per ASTM F19-11. There are two alumina buttons (white and purple) brazed to a Kovar ${ }^{\mathrm{TM}}$ spacer using the Ag-Cu-Zr filler metal.

The alumina/Ag-Cu-Zr/Kovar ${ }^{\mathrm{TM}}$ braze joint microstructure is shown in Fig. 4. The brazing parameters were $985^{\circ} \mathrm{C}\left(1805^{\circ} \mathrm{F}\right), 5 \mathrm{~min}$, and a 600 -torr argon (Ar) atmosphere. A reaction zone formed next to the $\mathrm{Ag}-\mathrm{Cu}-\mathrm{Zr} /$ alumina interface that was comprised of $\mathrm{ZrO}_{2}$ particles generated by the reduction/oxidation (redox) reaction between $\mathrm{Zr}$ from the filler metal and alumina. ${ }^{2} \mathrm{~A}$ consequence of the redox reaction is the release of elemental $\mathrm{Al}$ into the (molten) filler metal. At the Ag-Cu-Zr/Kovar ${ }^{\mathrm{TM}}$ interface (Fig. 5), energy-dispersive $\mathrm{x}$-ray (EDX) analysis identified three phases in the reaction layer to within the \pm 1 $\mu \mathrm{m}$ spatial resolution of that technique. There were two $(\mathrm{Fe}, \mathrm{Ni}, \mathrm{Co})_{\mathrm{x}}(\mathrm{Al}, \mathrm{Zr})_{\mathrm{y}}$ compositions, one higher in $\mathrm{Al}$ ("high$\mathrm{Al}^{\prime \prime}$ ) and the second composition lower in $\mathrm{Al}$ ("low-Al"). Between them was a $\mathrm{Zr}$ rich layer ("high-Zr") designated as (Fe, $\mathrm{Ni}, \mathrm{Co})_{\mathrm{x}}(\mathrm{Zr}, \mathrm{Al})_{\mathrm{y}}$. The presence or absence as well as thicknesses of these layers varied along the interface.

A quantitative analysis was made of reaction layer phases formed at the Ag$\mathrm{Cu}-\mathrm{Zr} / \mathrm{Kovar}^{\mathrm{TM}}$ interface using the elec-

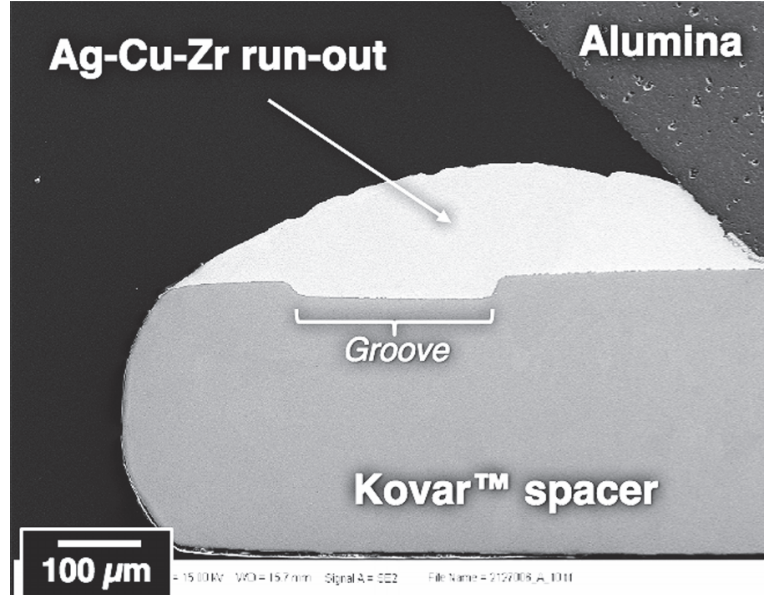

Fig. 2 - An SEM photograph shows the run-out material by metallographic cross section.

tron probe microanalysis (EPMA) technique. The plot in Fig. 6A shows the entire braze joint. The $\mathrm{Ag}-\mathrm{Cu}-$ $\mathrm{Zr} /$ Kovar $^{\mathrm{TM}}$ interface is magnified in Fig. 6B. The Fe trace shows a shallow peak (red arrow) next to the Kovar ${ }^{\mathrm{TM}}$ base material; it was accompanied by reduced $\mathrm{Ni}$ and Co signals. In the reaction layer, the positions of the low- and high-Al phases are indicated by the orange and cyan arrows, respectively. The Zr-rich phase is identified by the purple arrow; it also exhibited a significant $\mathrm{Al}$ content. The Ni signal showed a small peak at the $\mathrm{Zr}$ rich phase.

The EPMA plot in Fig. 6B was used to estimate the phase compositions. The error range was relatively wide at \pm 2 at.-\% due to the limited thickness of each layer vs. the x-ray sampling volume (1-2 $\mu$ m diameter). The $\mathrm{Fe}, \mathrm{Ni}$, and Co components were grouped together as one atomic fraction, $\mathrm{x}$, while $\mathrm{Al}$ and $\mathrm{Zr}$ (when present) were combined as the second group having an atomic fraction, $y$. The layer compositions were estimated to be

- $(\mathrm{Fe}, \mathrm{Ni}, \mathrm{Co})_{\mathrm{x}}(\mathrm{Al}, \mathrm{Zr})_{\mathrm{y}}$ (high-Al) $=(\mathrm{Fe}, \mathrm{Ni}, \mathrm{Co})_{2} \mathrm{Al} ; \mathrm{Al}=33$ at.-\%; $\mathrm{Zr} \approx 0$ at. $-\%$

$$
\begin{aligned}
& \text { - }(\mathrm{Fe}, \mathrm{Ni}, \mathrm{Co})_{\mathrm{x}}(\mathrm{Zr}, \mathrm{Al})_{\mathrm{y}}(\text { high-Zr }) \\
& =(\mathrm{Fe}, \mathrm{Ni}, \mathrm{Co})_{7}(\mathrm{Zr}, \mathrm{Al})_{3} ; \\
& \quad \mathrm{Al}=26 \text { at.- } \% ; \mathrm{Zr}=4 \text { at.-\% } \\
& \text { - }(\mathrm{Fe}, \mathrm{Ni}, \mathrm{Co})_{\mathrm{x}}(\mathrm{Al}, \mathrm{Zr})_{\mathrm{y}}(\mathrm{low}-\mathrm{Al}) \\
& =(\mathrm{Fe}, \mathrm{Ni}, \mathrm{Co})_{9} \mathrm{Al} ; \mathrm{Al}=10 \text { at.-\%; } \\
& \mathrm{Zr} \approx 0 \text { at.-\% }
\end{aligned}
$$

A transmission electron microscopy (TEM) sample was fabricated of the interface by focused ion-beam (FIB) sectioning. An elemental spectral image is provided in Fig. 7. Beside the three reaction layers above, the analysis also shows the Fe-rich layer next to the Ko$\operatorname{var}^{\mathrm{TM}}$ base material (red arrow in Fig. $6 \mathrm{~B})$. That layer is designated ( $\mathrm{Fe}, \mathrm{Ni}$, Co) ${ }_{\mathrm{x}} \mathrm{Al}_{\mathrm{y}}$. Quantitative TEM analysis would be required to determine the exact composition, but that evaluation was outside the scope of the present study.

Lastly, the EPMA data indicated Fe, $\mathrm{Ni}$, and $\mathrm{Co}$ as well as $\mathrm{Al}$ and $\mathrm{Zr}$ were completely absent from the $\mathrm{Ag}-\mathrm{Cu}-\mathrm{Zr}$ filler metal to within the detection limit. These elements were fully consumed in the reaction layer development (Fig. 5). Copper was present in the filler metal at its same bulk material concentration because it did not have a role in the reaction layer development.

\section{Run-Out Interface Metallurgy}

The photograph in Fig. 8A shows

\section{Footnote:}

2. This reaction is not spontaneous by the balance of free energies (Ref. 4). Rather, the solution activity of elemental Al in the molten filler metal provides the added driving force needed for spontaneity. 


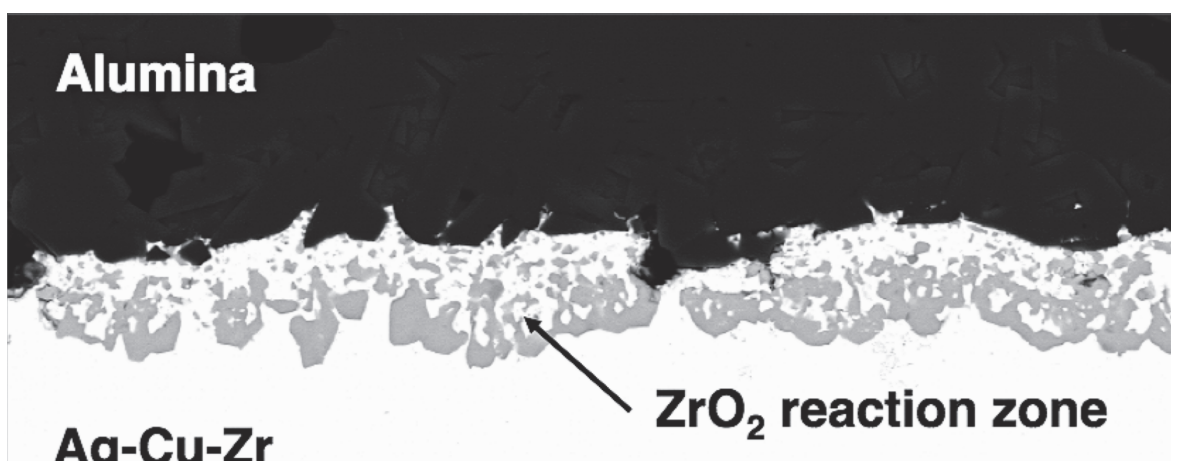

Reaction layers

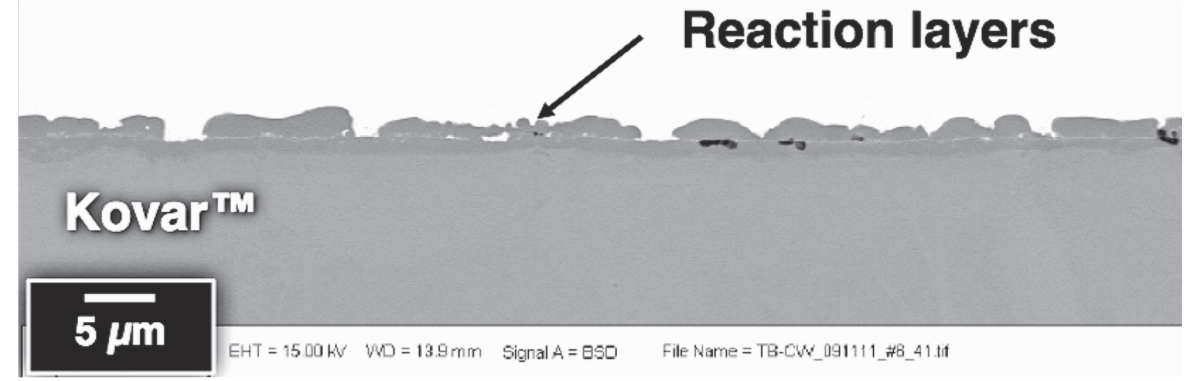

Fig. 4 - SEM photograph shows the overall microstructure of the alumina/Ag-Cu-

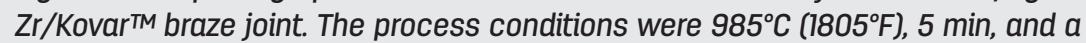
600-torr Ar atmosphere.

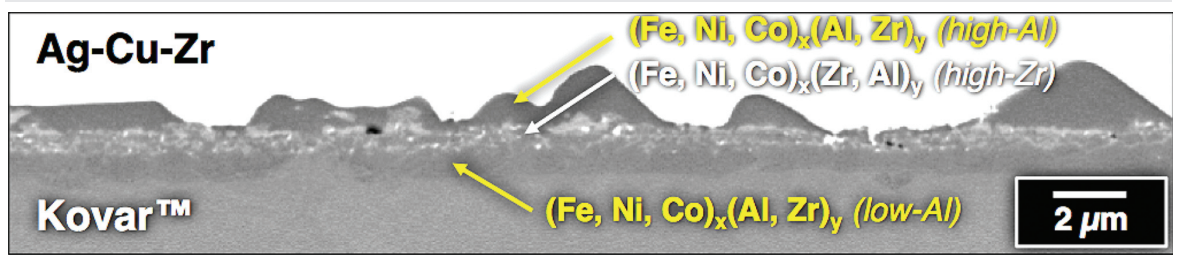

Fig. $5-A-S E M$ photograph identifies the phases in the reaction layer along the KovarTM/Ag-Cu-Zr interface [ $985^{\circ} \mathrm{C}\left(1805^{\circ} \mathrm{F}\right), 5 \mathrm{~min}, 600$-torr $\mathrm{Ar}$ ].

one side of an alumina/Ag-Cu- $\mathrm{Zr} /$ $\operatorname{Kovar}^{\mathrm{TM}}$ tensile test specimen that was pulled apart after brazing conditions at $985^{\circ} \mathrm{C}\left(1805^{\circ} \mathrm{F}\right)$ for $5 \mathrm{~min}$ in $600-$ torr Ar. The dashed circles outline the faying surface footprint. Run-out was present at location " 1 " and absent from location "2." The SEM photograph in Fig. 8B was taken at location "1." A reaction zone extended $40 \mu \mathrm{m}$ away from the edge of the $\mathrm{Ag}-\mathrm{Cu}-\mathrm{Zr}$ filler metal. There were three distinct surface morphologies labeled: "A," "B," and "C." Energy-dispersive $\mathrm{x}$-ray analyses indicated strong $\mathrm{Al}$ signals within regions " $B$ " and " $C$," which implies that they were comprised of the high-Al, $(\mathrm{Fe}, \mathrm{Ni}, \mathrm{Co})_{\mathrm{x}}(\mathrm{Al}, \mathrm{Zr})_{\mathrm{y}}$ phase. Conversely, region "A" was the low- $\mathrm{Al}$, ( $\mathrm{Fe}, \mathrm{Ni}$,

$\mathrm{Co})_{\mathrm{x}}(\mathrm{Al}, \mathrm{Zr})_{\mathrm{y}}$ phase. Zirconium was absent from all three regions.

A similar SEM analysis was performed on location $2-$ Fig. $8 \mathrm{C}$. The reaction phases formed an abrupt edge rather than the extended zone in Fig. 8B. An EDX analysis identified particles comprised of the high- $\mathrm{Zr}$ (Fe, Ni, $\mathrm{Co})_{\mathrm{x}}(\mathrm{Zr}, \mathrm{Al})_{\mathrm{y}}$ phase surrounded by both low-Al and high- $\mathrm{Al}(\mathrm{Fe}, \mathrm{Ni}, \mathrm{Co})_{\mathrm{x}}(\mathrm{Zr}, \mathrm{Al})_{\mathrm{y}}$ phases in addition to residual $\mathrm{Ag}-\mathrm{Cu}-\mathrm{Zr}$ filler metal. A metallographic cross section confirmed the presence of the $\mathrm{Zr}$ rich $(\mathrm{Fe}, \mathrm{Ni}, \mathrm{Co})_{x}(\mathrm{Zr}, \mathrm{Al})_{y}$ layer underneath the entire reaction layer footprint unlike the run-out region that showed only the high- and low-Al phases. The $\mathrm{Zr}$-rich $(\mathrm{Fe}, \mathrm{Ni}, \mathrm{Co})_{x}(\mathrm{Zr}, \mathrm{Al})_{\mathrm{y}}$ phase dominated the reaction layer in the non-runout region. This finding implies an association between run-out and the lowand high-Al phases in the reaction zone.

Run-out typically occurs at one, or at most, two locations per braze joint. The locations occur randomly around the joint. This behavior suggests that, once a run-out "event" has taken place, the driving force is reduced for any further such activities. Since it seems unlikely that the specific condition responsible for run-out is limited to one or two locations, the loss of driving force is likely coupled to the added surface energy resulting from creation of the run-out lobe.

\section{Geometry Effect}

The role of surface energy was examined by considering the effect of braze joint geometry using the tension test sample - Fig. 3. The test matrix is described by the four cells in Fig. 9A. The upper left-hand cell represents the "all-

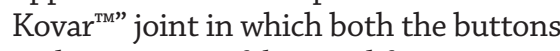
and spacer were fabricated from Ko$\mathrm{var}^{\mathrm{Tm}}$. The upper right-hand cell (blue) is the baseline case - alumina buttons and a Kovar ${ }^{\mathrm{TM}}$ spacer. The lower lefthand cell is the reverse to the baseline condition by having Kovar ${ }^{\mathrm{TM}}$ buttons and alumina spacer. Lastly, there is the "all-ceramic" sample (lower right-hand cell) that has both buttons and spacer constructed of alumina. The buttons and spacers were brazed together using a 51- $\mu$ m-(0.002-in.-) thick Ag-Cu-Zr filler metal preform. The process conditions were $985^{\circ} \mathrm{C}\left(1805^{\circ} \mathrm{F}\right), 5 \mathrm{~min}$, and 600-torr Ar. The joint clearance was controlled by dimples placed in the Ko$\mathrm{var}^{\mathrm{TM}}$ spacer. In the case of the alumina ceramic spacer, 25.4- $\mu \mathrm{m}$ - (0.001-in.-) thick Kovar $^{\mathrm{TM}}$ ribbons controlled the joint clearence. Duplicate samples were fabricated for each case. After brazing, each sample was inspected for run-out.

The occurrence of run-out is summarized by the schematic diagram in Fig. 9B. Only the baseline sample exhibited run-out. The absence of run-out in the all-Kovar $^{\mathrm{TM}}$ braze joints confirmed that elemental $\mathrm{Al}$ was required for run-out to take place. The $\mathrm{Zr}$ component of the $\mathrm{Ag}$ $\mathrm{Cu}-\mathrm{Zr}$ filler metal formed $\mathrm{Zr}$-rich ( $\mathrm{Fe}$, $\mathrm{Ni}, \mathrm{Co})_{\mathrm{x}}(\mathrm{Zr}, \mathrm{Al})_{\mathrm{y}}$ phase at the two $\mathrm{Ag}-\mathrm{Cu}-$ $\mathrm{Zr} /$ Kovar $^{\mathrm{TM}}$ interfaces. The absence of run-out concurred with the earlier discussion about Fig. 8C that this phenomenon is not supported by the $\mathrm{Zr}$-rich reaction layer.

The test sample having Kovar $^{\mathrm{TM}}$ buttons and a ceramic spacer did not exhibit run-out. The fillet is shown in Fig. $10 \mathrm{~A}$ from one braze joint. The top edge of the fillet (yellow box) is shown at higher magnification in Fig. 10B, along with the corresponding Al EDX map. The SEM and EDX analyses identified the high- $\mathrm{Al}(\mathrm{Fe}, \mathrm{Ni}, \mathrm{Co})_{\mathrm{x}}(\mathrm{Al}, \mathrm{Zr})_{\mathrm{y}}$ reaction 

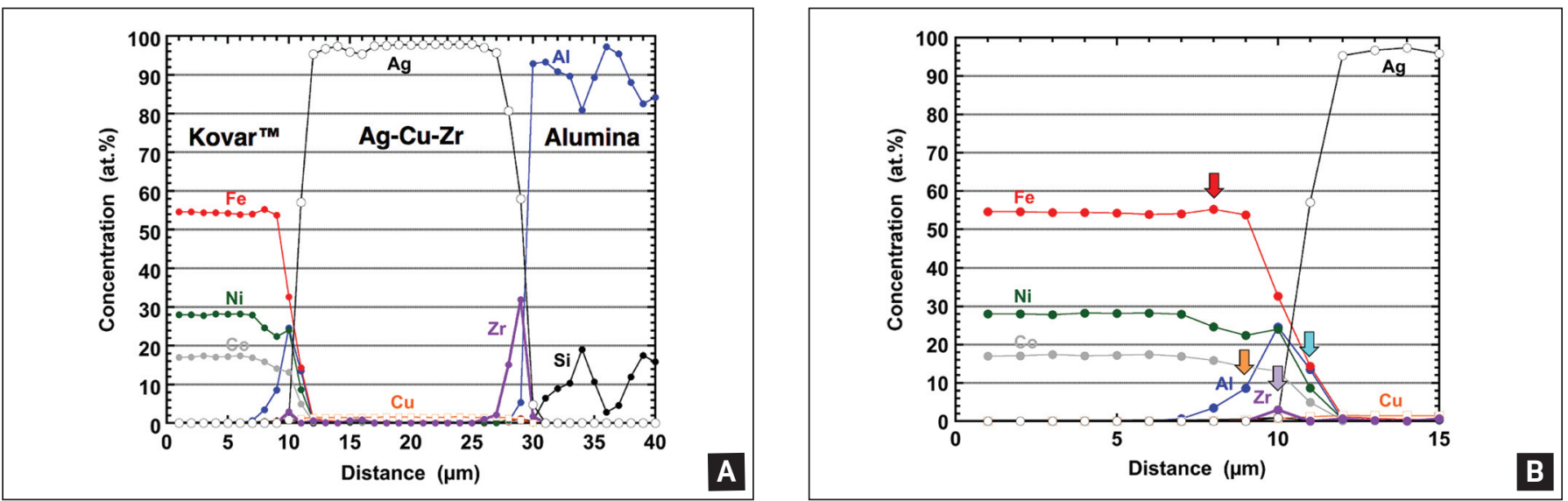

Fig. 6-A - Electron probe microanalysis (EPMA) plot shows the elemental concentration profiles across the KovarTM/Ag-Cu$\mathrm{Zr} /$ alumina braze joint [ $985^{\circ} \mathrm{C}\left(1805^{\circ} \mathrm{F}\right), 5 \mathrm{~min}, 600$ torr Ar.] B - Magnified view shows the $\mathrm{Ag}$-Cu-Zr/KovarTM interface reaction layer. The red arrow identifies the shallow Fe peak ( $8 \mu \mathrm{m}$ position) while the orange arrow $(9 \mu \mathrm{m})$ and cyan arrow $(11 \mu \mathrm{m})$ indicate the low-Al and high-Al phases, respectively. The purple arrow points to the high-Zr phase.

layer, which reached up the Kovar ${ }^{\mathrm{TM}}$ button side wall well beyond the edge of the $\mathrm{Ag}-\mathrm{Cu}-\mathrm{Zr}$ fillet. Yet run-out was absent.

An explanation for the absence of run-out in Fig. 10B is based on the schematic diagram in Fig. 10C. The solid blue line marks the limit of the solder fillet. The fillet shape, which is required to support run-out up the Kovar ${ }^{\mathrm{TM}}$ button side wall, is described by the dashed blue trace. That fillet geometry, which is controlled by the molten $\mathrm{Ag}-\mathrm{Cu}-\mathrm{Zr}$ surface tension, would require the filler metal to wet an additional distance " $\mathrm{A}$ " farther out on the alumina surface. However, the $\mathrm{Ag}-\mathrm{Cu}-\mathrm{Zr}$ active braze alloy cannot spontaneously spread on the ceramic surface. Therefore, although a reaction layer was generated between $\mathrm{Al}$ and the Kovar ${ }^{\mathrm{TM}}$ base material that would support run-out, the molten filler metal's surface tension prevented the latter from taking place.

The final configuration was the allalumina test specimen. As expected, the redox reaction took place at both $\mathrm{Ag}$ $\mathrm{Cu}-\mathrm{Zr}$ /alumina interfaces, generating elemental Al. Run-out was not observed, which confirmed the need for the Ko$\operatorname{var}^{\mathrm{TM}}$ base material and its reaction with $\mathrm{Al}$. The $\mathrm{Al}$ released by the redox reaction remained in the filler metal. Electron probe microanalysis (EPMA) determined the elemental Al content to be $0.7-0.9$ wt-\%. These $\mathrm{Al}$ concentrations formed the basis of the test program described later in this report.

In summary, the above findings confirmed two critical aspects of run-out. First, the primary driving force is the reaction between the Kovar ${ }^{\mathrm{TM}}$ base materi-

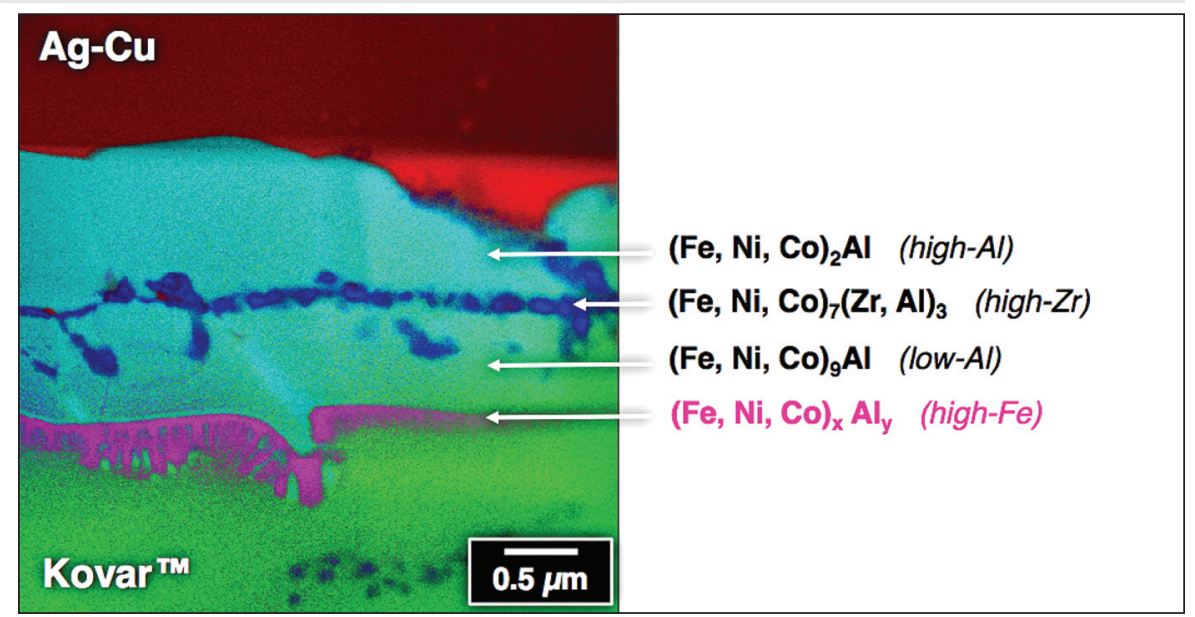

Fig. 7-Spectral image (TEM) shows the reaction layers at the KovarTM/Ag-Cu-Zr interface, including the high-Fe layer.

$\mathrm{al}$ and $\mathrm{Al}$ released by the redox reaction. The reaction between $\mathrm{Kovar}^{\mathrm{TM}}$ and $\mathrm{Zr}$ did not support run-out. Secondly, the surface energy of molten filler metal is of a magnitude, which when combined with braze joint geometry (and gravity), can affect the run-out event. The ineffectiveness of the groove in Fig. 2 to curtail run-out provides a size scale below which geometric contingencies (here, sharp corners) are ineffective.

\section{Present Study}

The present study was undertaken to understand the role of $\mathrm{Al}$ and its reaction with $\mathrm{Kovar}^{\mathrm{TM}}$ as the underlying mechanism responsible for run-out. Test filler metals were fabricated by making $\mathrm{Al}$ additions to a $100 \mathrm{Ag}$ filler metal. Because the review, above, concluded that neither $\mathrm{Cu}$ nor $\mathrm{Zr}$ had ex- plicit roles in the run-out phenomenon, they were not included in the filler metal. The second objective was to investigate the effect of sample geometry. Two test sample configurations were used for this effort: $a$ ) the sessile drop and $b$ ) the $\operatorname{Kovar}^{\mathrm{TM}} / \mathrm{Ag}-\mathrm{xAl} / \mathrm{Kovar}^{\mathrm{TM}}$ braze joint. The sessile drop results are presented in this Part 1 report; the braze joint data will be described in Part 2. The longterm goal is to use these results to develop one or more mitigation strategies that would eliminate the occurrence of the run-out phenomenon.

\section{Experimental Procedures}

\section{Base Material}

The base material was a Kovar ${ }^{\mathrm{TM}}$ disk measuring $19.2 \mathrm{~mm}$ (0.75 in.) in 


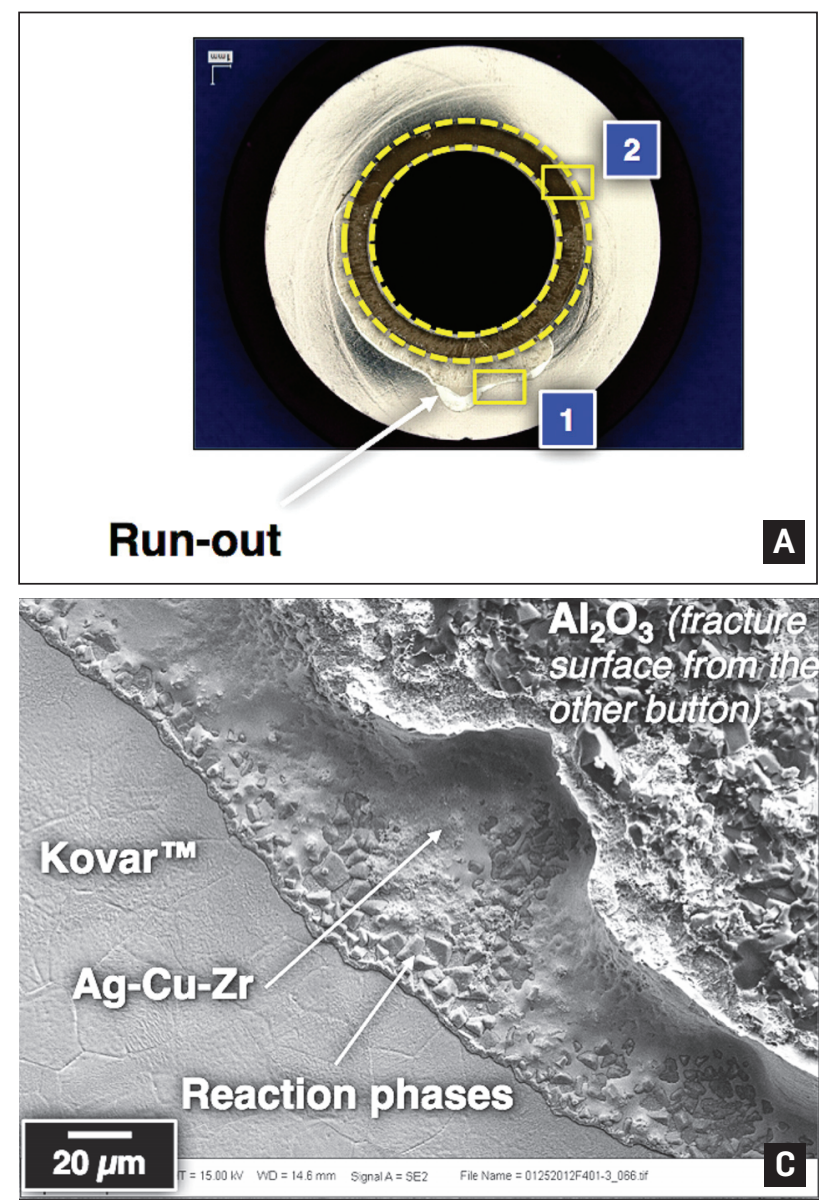

diameter and $0.56 \mathrm{~mm}(0.022 \mathrm{in}$.$) in$ thickness. The surface roughness was measured at two locations using a laser scanning microscope. The $\mathrm{S}_{\mathrm{a}}$ values were $0.916 \mu \mathrm{m}\left(3.6 \times 10^{-5} \mathrm{in}.\right)$ and $0.920 \mu \mathrm{m}\left(3.6 \times 10^{-5} \mathrm{in}.\right)$.

\section{Filler Metal}

The filler metal variants began with

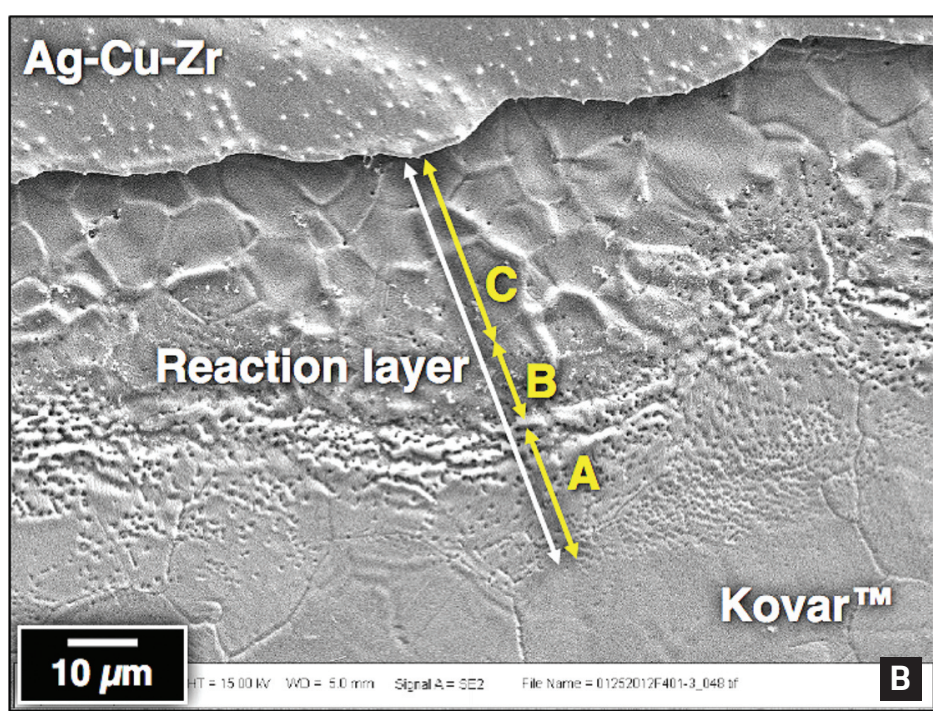

Fig. 8-A - Photograph shows a tensile test sample that was pulled apart. The dashed circles identify the footprint of the faying surfaces. Run-out is observed at location " " " on the KovarTM spacer [985 ${ }^{\circ} \mathrm{C}\left(1805^{\circ} \mathrm{F}\right), 5 \mathrm{~min}$, and 600 torr Ar] Location "2" did not have run-out. B - SEM image shows the edge of the run-out at "7". A reaction zone (white arrow) was comprised of three surface morphologies: A, B, and C. C-SEM image shows the edge of the filler metal at " 2 " where run-out was absent.

a $100 \mathrm{Ag}$ preform that was $51 \mu \mathrm{m}$ (0.002 in.) thick and $3.0 \mathrm{~mm}(0.13$ in.) in diameter. Aluminum additions were made by successfully depositing an $\mathrm{Al}$ coating onto one surface of the preform using the evaporation technique. Aluminum layer thicknesses were $22 \mu \mathrm{m}\left(8.7 \times 10^{-4} \mathrm{in}\right.$.), 11 $\mu \mathrm{m}\left(4.3 \times 10^{-4}\right.$ in.), and $4.4 \mu \mathrm{m}(1.7 \times$ $10^{-4} \mathrm{in}$.), which rendered $\mathrm{Al}$ concentrations of 10,5 , and $2 \mathrm{wt}-\%$. These concentrations were selected based upon the $\mathrm{Al}$ concentration of $0.7-0.9 \mathrm{wt}-\%$ observed in the filler metal of the allalumina samples and the hypothesis that run-out is caused by a localized excess of $\mathrm{Al}$. The range of $2-10 \mathrm{wt}-\%$ provided an upper bound, which considered those two premises.

\section{Brazing Process}

Duplicate sessile drop test samples were brazed under one of the four combinations of temperature, $965^{\circ}$ or $995^{\circ} \mathrm{C}$ $\left(1769^{\circ}\right.$ or $\left.1823^{\circ} \mathrm{F}\right)$, and time duration, 5 or $20 \mathrm{~min}$. The brazing process ramp
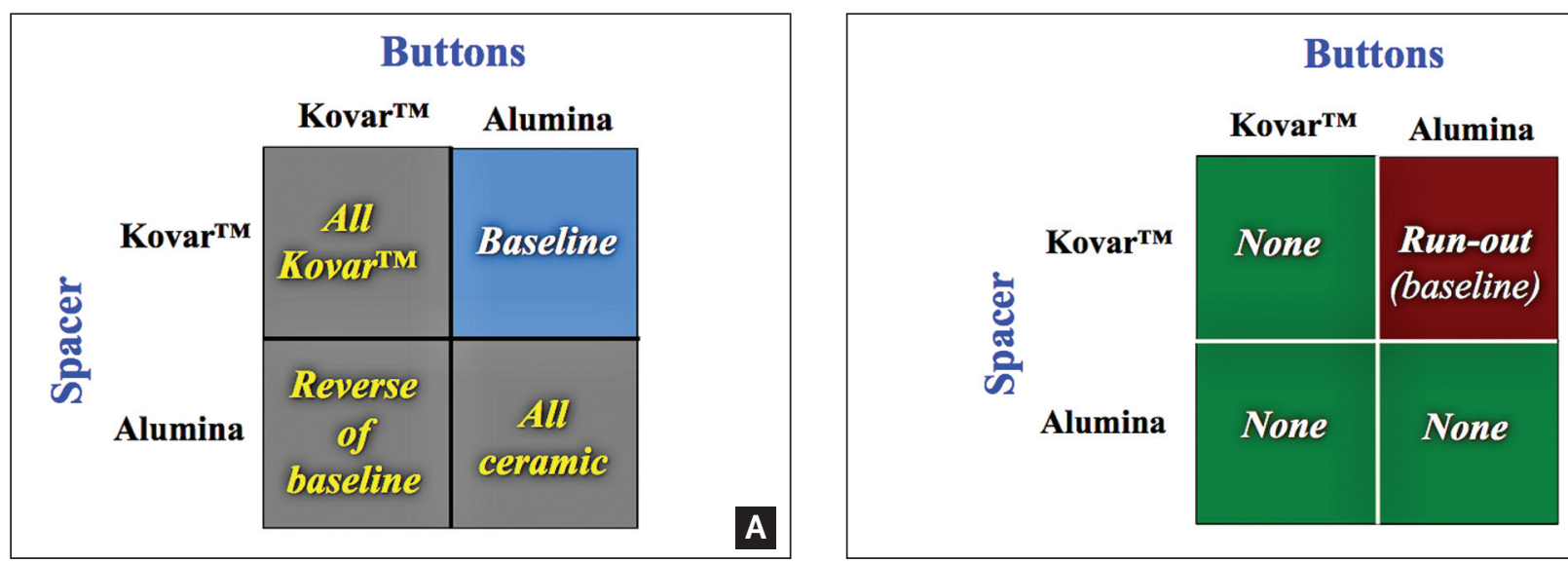

Fig. 9-A - Schematic identifies the four variants of button and spacer materials used to investigate the geometry effect. BThe same diagram shows the presence (red) or absence (green) of run-out after the brazing step. 


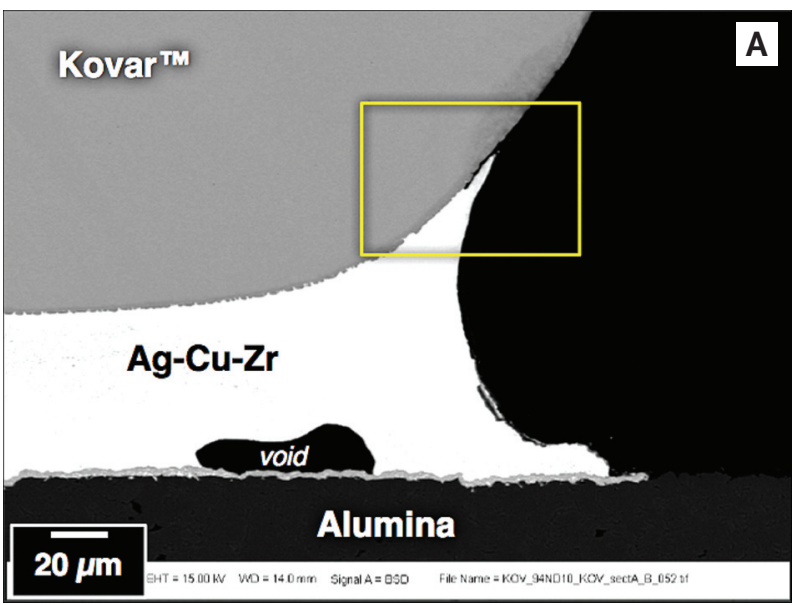

rates were as follows: a) $10^{\circ} \mathrm{C} / \mathrm{min}$ ( $\left.18^{\circ} \mathrm{F} / \mathrm{min}\right)$ from $25^{\circ}$ to $900^{\circ} \mathrm{C}\left(77^{\circ}\right.$ to $\left.1652^{\circ} \mathrm{F}\right)$; b) $5^{\circ} \mathrm{C} / \mathrm{min}\left(9^{\circ} \mathrm{F} / \mathrm{min}\right)$ from $900^{\circ} \mathrm{C}\left(1652^{\circ} \mathrm{F}\right)$ to the peak temperature; c) $20^{\circ} \mathrm{C} / \mathrm{min}\left(36^{\circ} \mathrm{F} / \mathrm{min}\right)$ from the peak temperature to approximately $750^{\circ} \mathrm{C}\left(1382^{\circ} \mathrm{F}\right)$; and $\left.\mathrm{d}\right)$ an average of $10^{\circ} \mathrm{C} / \mathrm{min}\left(18^{\circ} \mathrm{F} / \mathrm{min}\right)$ from $750^{\circ}$ to $400^{\circ} \mathrm{C}\left(1382^{\circ}\right.$ to $\left.752^{\circ} \mathrm{F}\right)$. All brazing operations were performed under a high vacuum of better than $10^{-7}$ torr to prevent oxidation of the $\mathrm{Al}$ coating. The drawback of using high vacuum was the evaporation of Ag from the molten sessile drop, particularly at the higher brazing temperature and longer time. The loss of Ag did not affect the reactions between $\mathrm{Al}$ and $\mathrm{Kovar}^{\mathrm{TM}}$ base material because those reactions occurred very rapidly (Ref. 1).

The sessile drop test samples were fabricated by having the side of the preform with the Al film placed away from the Kovar ${ }^{\mathrm{TM}}$ surface. This configuration simulated the requirement for Al to "cross" the molten filler metal to reach the Kovar ${ }^{\mathrm{TM}}$ interface as in the actual Kovar ${ }^{\mathrm{TM}}$-to-alumina braze joint.

\section{Specimen Analysis}

The sessile drop samples were first inspected for run-out as the latter appears in Fig. 1. Then the specimens were examined using the SEM. Qualitative chemical analyses were obtained by the EDX technique. Next, the sessile drops were cross sectioned using standard metallographic techniques. Once again, EDX analysis provided qualitative elemental summaries of the interface microstructures. Electron probe microanalysis (EPMA) provided quantitative compositional assessments by taking traces across the Kovar ${ }^{\mathrm{TM}} /$ filler metal in-
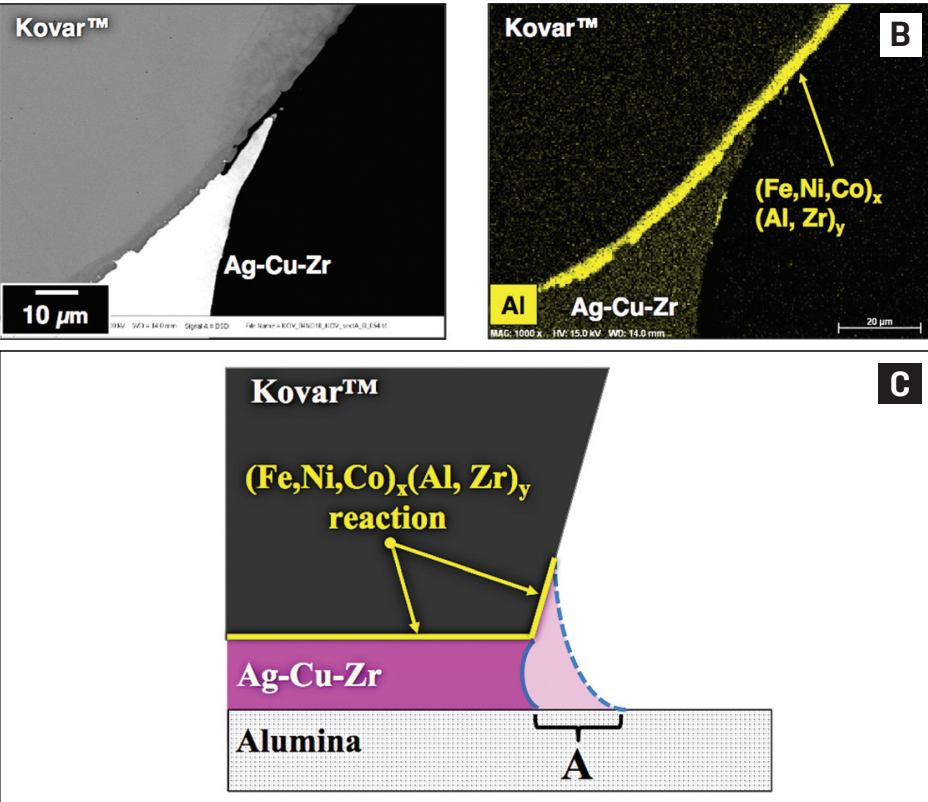

c

terface reaction layers. The traces were continued for a distance into both the filler metal and Kovar $^{\mathrm{TM}}$ base material beyond the immediate reaction layer. The accelerating voltage was $15 \mathrm{keV}$ and the beam current was 20 $\mathrm{nA}$. Data acquisition was performed in $0.5-\mu \mathrm{m}$ steps with the understanding that the spatial resolution is limited by the $\mathrm{x}$-ray sampling volume of a diameter of 1-2 $\mu \mathrm{m}$. Triplicate traces were performed for each analysis.

\section{Results}

\section{Analysis of the Sessile Drop Surfaces}

Photographs show one of the duplicate sessile drop samples representing the four $\mathrm{Al}$ contents in Fig. 11. The brazing time was 5 min (vacuum) and the brazing temperatures were $965^{\circ} \mathrm{C}$ $\left(1769^{\circ} \mathrm{F}\right)$ for Fig. $11 \mathrm{~A}$ and $995^{\circ} \mathrm{C}$ $\left(1823^{\circ} \mathrm{F}\right)$ for Fig. 11B. The wettingand-spreading behavior was uniform over the base material surface with respect to the size scale of the surface roughness topography. At either brazing temperature, the sessile drop footprint increased monotonically with $\mathrm{Al}$ content. The Ag-0Al sessile drop experienced nonwetting at $965^{\circ} \mathrm{C}\left(1769^{\circ} \mathrm{F}\right)$ and only wetting, but without observable spreading, at $995^{\circ} \mathrm{C}\left(1823^{\circ} \mathrm{F}\right)$.
Otherwise, the wetting and spreading did not differ significantly between the two temperatures. Run-out, as is exemplified in Fig. 1, was not observed in any of the samples.

Generally, increasing the brazing time to 20 min caused the sessile drop footprints to be comparable to, or only slightly greater than, those observed after $5 \mathrm{~min}$. This trend suggests that the Ag-xAl/Kovar ${ }^{\mathrm{TM}}$ reaction layer was largely completed well before even the five-minute interval.

A more detailed discussion is presented below of the physical metallurgy of each sessile drop composition.

$$
A g-x A l, x=0 \text { and } 2 w t-\%
$$

The SEM and EDX surface analyses began with the Ag-xAl alloys ( $\mathrm{x}=0$ or 2 wt-\%) brazed at $965^{\circ} \mathrm{C}\left(1769^{\circ} \mathrm{F}\right)$ for 5 min. As noted above, the $100 \mathrm{Ag}$ filler metal did not wet the Kovar ${ }^{\mathrm{TM}}$ base material - Fig. 11A. The Ag-2Al sessile drop is shown in Fig. 12. The inset photograph indicates the location (yellow box) of the higher magnification SEM photograph. The two locations, "A" and " $B$ " were investigated further, 


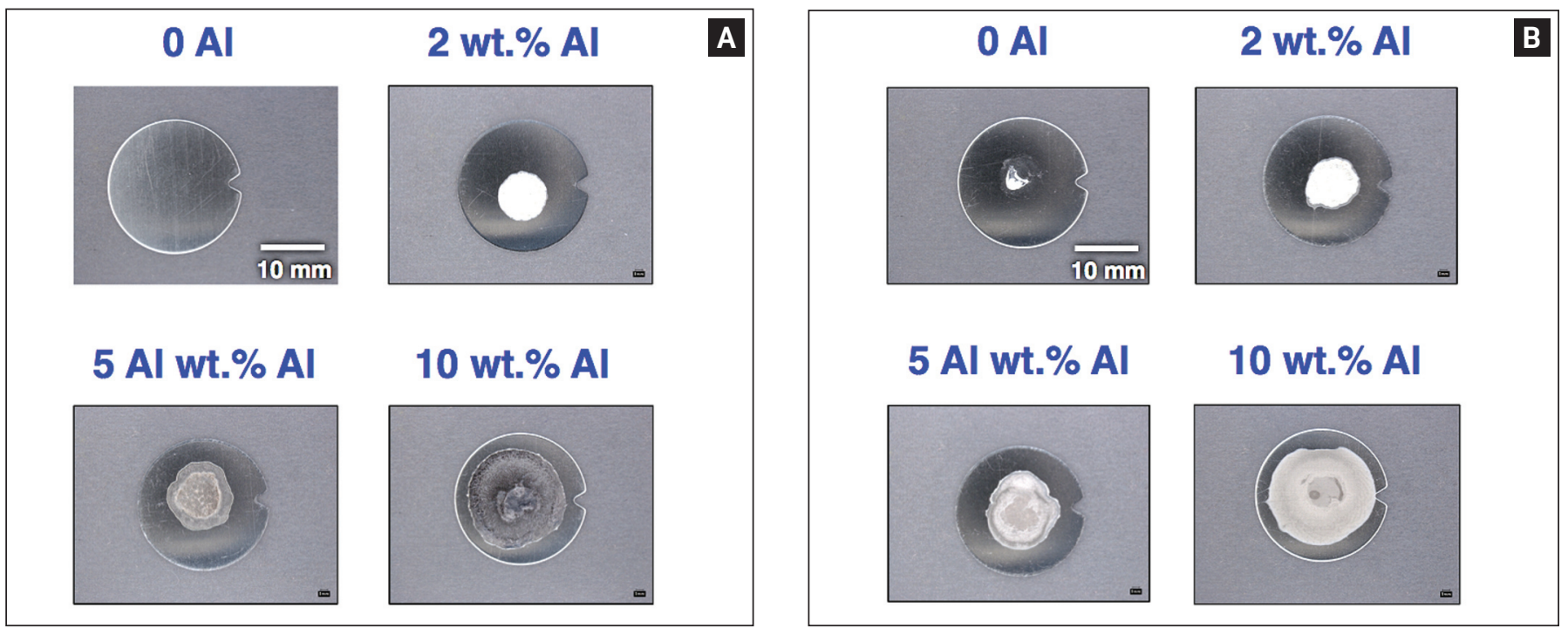

Fig. 11 - Photographs show the sessile drop samples for Ag-xAl alloys, $x=0,2,5$, and $10 w t-\%$, that were fabricated at $-A-$ $965^{\circ} \mathrm{C}\left(1769^{\circ} \mathrm{F}\right) ; \mathrm{B}-995^{\circ} \mathrm{C}\left(1823^{\circ} \mathrm{F}\right)$. The brazing time was 5 min (vacuum).

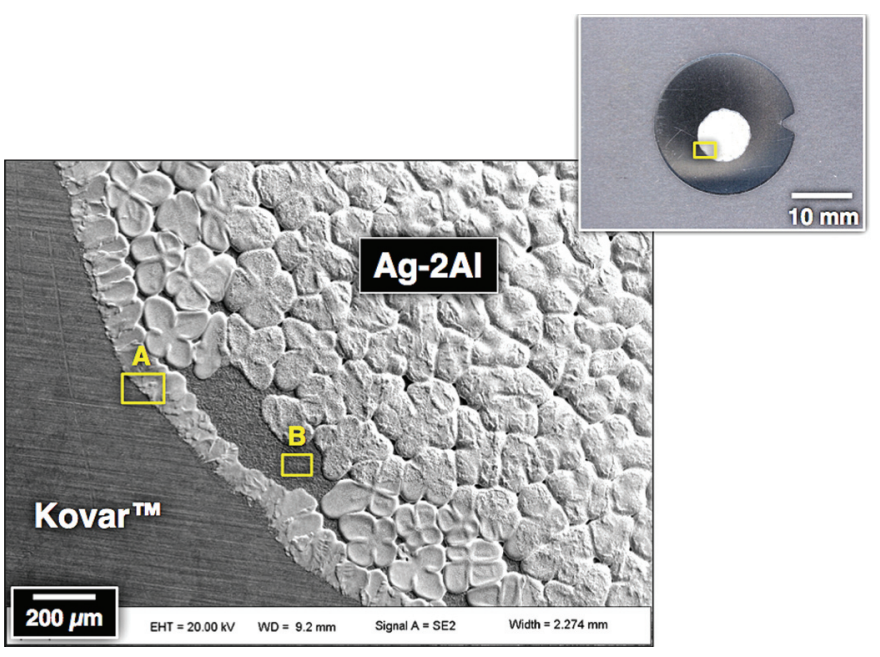

Fig. 12 - SEM image shows the edge of the Ag-2Al sessile drop made at $965^{\circ} \mathrm{C}\left(1769^{\circ} \mathrm{F}\right)$ and $5 \mathrm{~min}$. The image location is indicated by the yellow box in the inset photograph. Two regions of interest are indicated as "A" and "B."

beginning with "A," which is shown at higher magnification in Fig. 13. The reaction layer topography was visible 10-15 $\mu \mathrm{m}$ from the Ag-2Al edge and was comprised of $\mathrm{Al}, \mathrm{Fe}, \mathrm{Ni}$, and $\mathrm{Co}$ as shown by the EDX maps in Fig. 14. $\mathrm{The} \mathrm{Fe}, \mathrm{Ni}$, and Co contents were lower than, higher than, and similar to, respectively, the nominal Kovar ${ }^{\mathrm{TM}}$ com- $^{-}$ position. Although difficult to distinguish in Fig. 14, there was a thin Ferich zone that bordered the reaction layer and $\mathrm{Kovar}^{\mathrm{TM}}$ base material. Aluminum was not detected in the filler metal above the background signal. These observations are like those col-

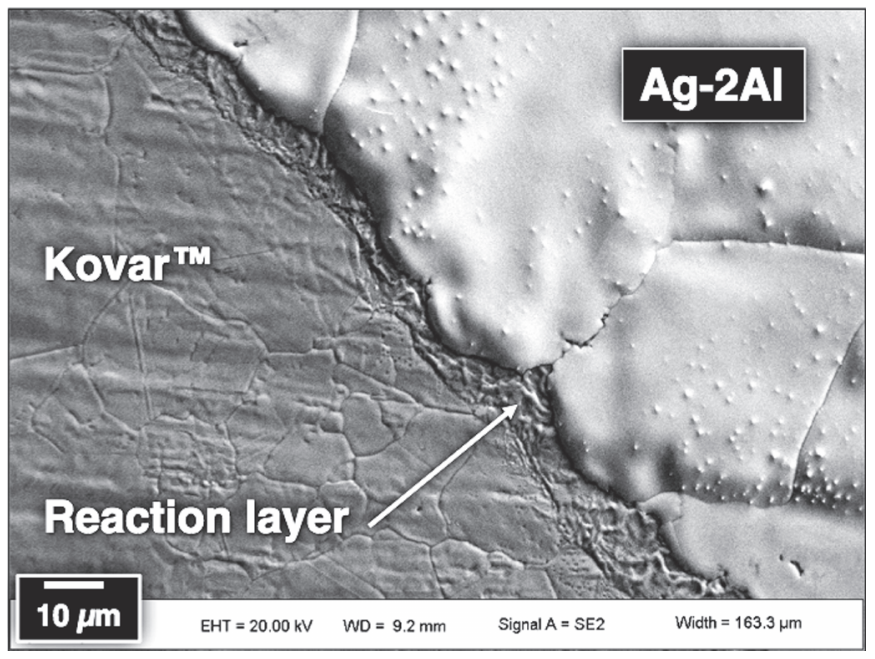

Fig. 13 - SEM photograph shows the location "A" of the Ag2 Al sample of Fig. 12 at higher magnification.

lected for reaction layers in the alumina/Ag- $\mathrm{Cu}-\mathrm{Zr} / \mathrm{Kovar}^{\mathrm{TM}}$ base metal case (Ref. 1). This similarity underscores the ability of the Ag-xAl/Ko$\mathrm{var}^{\mathrm{TM}}$ base metal reactions to represent those of the $\mathrm{Ag}-\mathrm{Cu}-\mathrm{Zr}$ active braze alloy.

The area "B" in Fig. 12 shows the exposed reaction layer due to a localized evaporation of the filler metal that is thinner at the sessile drop edge. A high-magnification SEM photograph is provided in Fig. 15. The reaction layer exhibited a grain-like topography. The EDX analysis confirmed it to be comprised of $\mathrm{Fe}, \mathrm{Ni}, \mathrm{Co}$, and $\mathrm{Al}$. The grain boundary-like artifact had a slightly higher Fe concentration and, correspondingly, lower $\mathrm{Ni}$ and $\mathrm{Co}$ contents than the interior areas. The $\mathrm{Al}$ content was constant across the topography. Cracks were not observed in the reaction layer.

Increasing the brazing time to 20 min at $965^{\circ} \mathrm{C}\left(1769^{\circ} \mathrm{F}\right)$ caused a slightly greater degree of Ag-2Al evaporation. However, the exposed reaction layer maintained the same topography as that observed in Fig. 15. Also, the EDX elemental maps did not change for a longer brazing time.

The Ag- $x A l$ sessile drops having $\mathrm{x}=$ 0 and 2 were examined that were made under the brazing conditions of $995^{\circ} \mathrm{C}$ $\left(1823^{\circ} \mathrm{F}\right)$ and $5 \mathrm{~min}$. The Ag-OAl filler 

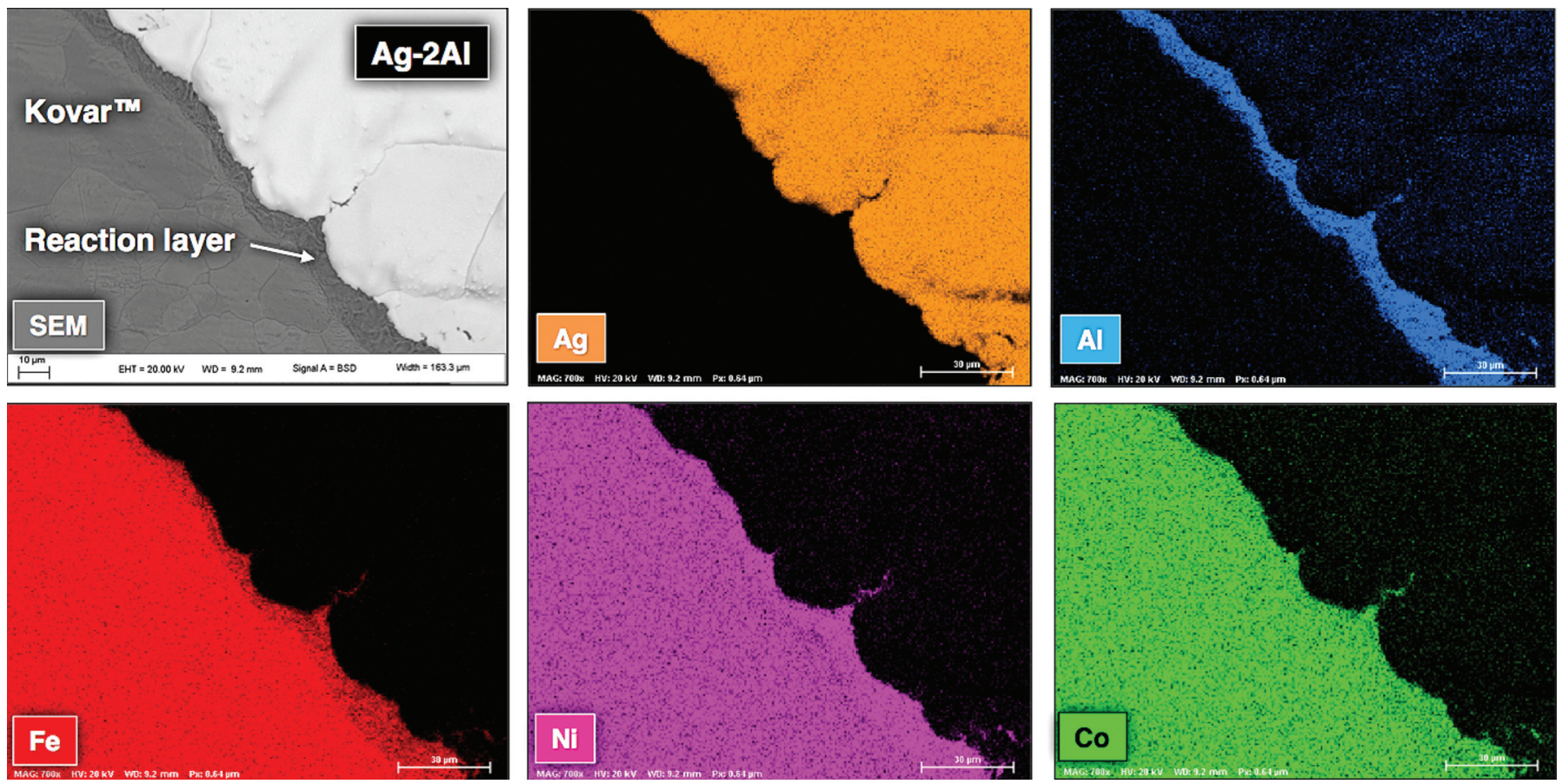

Fig. 14 - SEM photograph and corresponding EDX maps show the distributions of $\mathrm{Ag}, \mathrm{Al}, \mathrm{Fe}, \mathrm{Ni}$, and Co at the edge of the sessile belonging to the $\mathrm{Ag}-2 \mathrm{Al}$ sample $\left[965^{\circ} \mathrm{C}\left(1769^{\circ} \mathrm{F}\right), 5 \mathrm{~min}\right]$.

metal showed limited wetting of the Kovar $^{\mathrm{TM}}$ base material — Fig. 11B. The filler metal did not spread or exhibit a reaction layer at the edge of the sessile drop.

The morphology of the Ag-2Al sessile drop was like that shown in Fig. 12. The only difference was a slightly wider expanse of the exposed reaction layer (location "B") due to filler metal evaporation. The EDX maps in Fig. 14 were equally representative of the sessile drop edge. The reaction layer exhibited the same topography as shown in Fig. 15.

The brazing time was increased to 20 $\min \left[995^{\circ} \mathrm{C}\left(1823^{\circ} \mathrm{F}\right)\right]$. The Ag-OAl alloy wet the Kovar ${ }^{\mathrm{TM}}$ surface and formed a sessile drop, but it did not spread beyond the preform footprint. A reaction layer was not observed at the edge of the Ag-OAl sessile drop. The Ag-2Al sessile drop is shown in Fig. 16A. The yellow box indicates the location of the SEM image in Fig. 16B. The remaining filler metal "islands" (light) were $100 \mathrm{Ag}$ to within the EDX detection limit. The reaction layer (dark), which was exposed by filler metal evaporation, is shown at higher magnification in Fig. $16 \mathrm{C}$. The reaction layer topography was like that in Fig. 15, and it exhibited identical EDX maps. Cracks were not observed in the reaction layer.
$A g-\chi A l, x=$ 5 and $10 w t-\%$

The Ag-5Al sessile drop, which was formed at $965^{\circ} \mathrm{C}$ $\left(1769^{\circ} \mathrm{F}\right)$ and 5 min, had the filler metal cover the reaction layer except at the edge where the latter extended out by approximately $10 \mu \mathrm{m}$. The EDX analysis confirmed the reaction layer there had the same elemental distributions as were observed in Fig. 14.

When the brazing time was lengthened to $20 \mathrm{~min}\left[965^{\circ} \mathrm{C}\left(1769^{\circ} \mathrm{F}\right)\right]$, the Ag-5Al filler metal was completely lost from the sessile drop. The photograph in Fig. 17A identifies the edge and central regions, which are shown by the high-magnification SEM images in Fig. 17B, C, respectively. Three distinct topographies characterized the reaction layer in Fig. 17B. The "A" region has a mottled appearance while the " $B$ " region has a relatively smooth topography. The " $C$ " region, which had a topography like that in Fig. 15, extended to the interior of the footprint. The EDX analysis determined the reaction layer had elemental distributions like those observed for the Ag-2Al filler metal.

Figure $17 \mathrm{C}$ presents the first instance in which cracks were observed in the reaction layer (magenta arrows). Cracks suggest the presence of tensile 

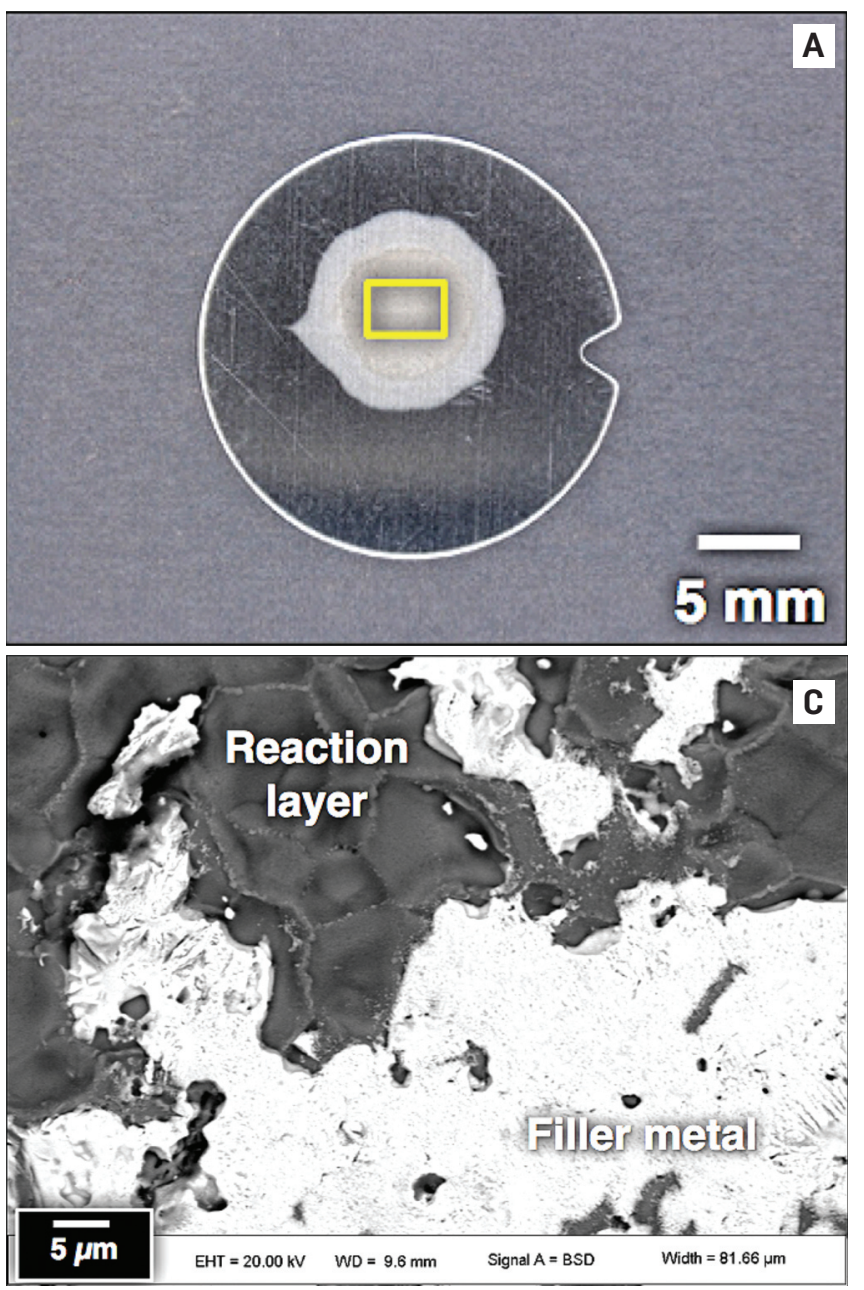

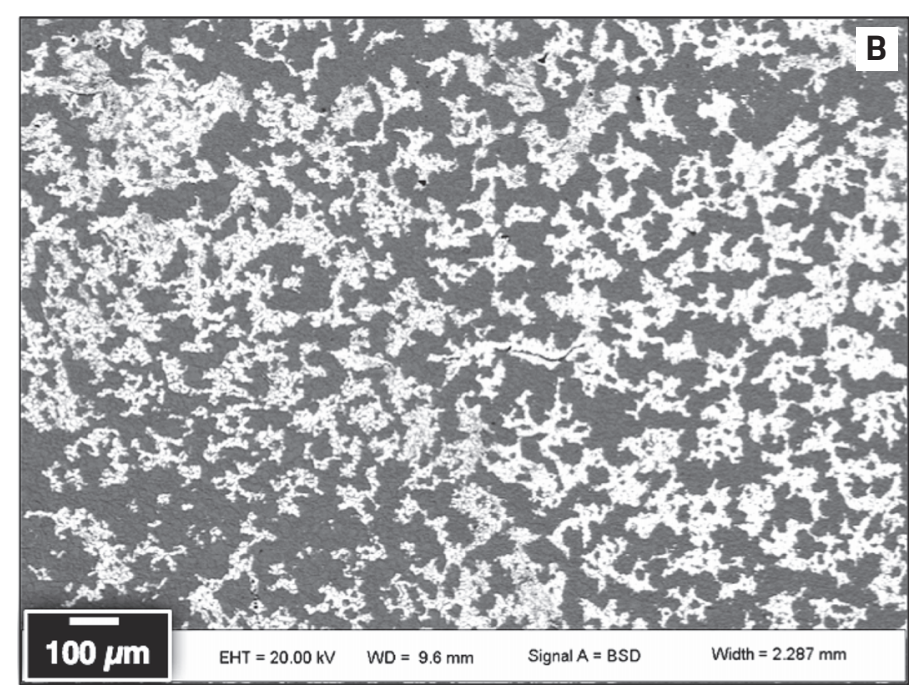

Fig. $16-A-$ Photograph shows the sessile drop created by the Ag-2Al filler metal brazed at $995^{\circ} \mathrm{C}\left(1823^{\circ} \mathrm{F}\right)$ for $20 \mathrm{~min}$. The yellow box indicates the location of the SEM image in B. B SEM photograph shows the mixture of exposed reaction layer (dark) and remaining filler metal (light). C - High-magnification SEM photograph highlights the reaction layer topography. residual stresses in the layer. A likely source of those stresses is the mismatch of coefficients of thermal expansion (CTE) between the reaction layer and base material. The assumption is made that the reaction layer can be suitably represented by the $\mathrm{Ni}_{3} \mathrm{Al}$ composition that has a CTE = 12-15 ppm/K (Ref. 5). Kovar $^{\mathrm{TM}}$ has a CTE = 5-7 ppm/K (Ref. 6). Upon cooling from the brazing temperature, the faster contraction of the reaction layer is hindered by the Kovar ${ }^{\mathrm{TM}}$ base material, resulting in tensile residual stresses in the former that are responsible for the cracks.

The Ag-5Al sessile drop was analyzed after brazing at $995^{\circ} \mathrm{C}\left(1823^{\circ} \mathrm{F}\right)$. The reaction layer topographies were nearly identical between the 5 and 20 min brazing times and did not differ from those observed at the lower brazing temperature (e.g., Fig. 17B, C).

The analysis turned to the Ag-10Al filler metal samples. After brazing at $965^{\circ} \mathrm{C}\left(1769^{\circ} \mathrm{F}\right)$ for $5 \mathrm{~min}$, a significant layer of filler metal covered the reaction layer. Regions of exposed reaction layer $\left(1769^{\circ} \mathrm{F}\right)$ - Fig. 18. The yellow boxes in Fig. 18A indicate the areas of higher magnification shown in Fig. 18B, C. The "B/A" and "C" topographies in Fig. 18B are identical to the "A," "B," and " $C$ " regions in Fig. 17B, including the existence of cracks in "C." The EDX technique did not find differences in reaction layer compositions when compared to those of the other Ag-xAl filler metals or brazing parameters discussed above.

However, the "D" and " $E$ " regions in Fig. $18 \mathrm{C}$ were unique to the $\mathrm{Ag}-10 \mathrm{Al}$ reaction layer. The "D" topography, which is shown at higher magnification in Fig. 19A, had a mottled appearance superimposed on the previously observed, grain-like structure. Cracks were prevalent in this reaction layer (magenta arrows). The "E" region is shown in Fig. 19B. Spheroid-like features were added to the same topography observed in "D." Cracks were present in the " $E$ " region (magenta arrows).

The reaction layer topographies illustrated in Figs. 18 and 19 were also observed on the Ag-10Al specimens created at $995^{\circ} \mathrm{C}\left(1823^{\circ} \mathrm{F}\right)$ and for either 5 or 20 min brazing times.

Several important observations can be summarized, below, that were compiled from the surface SEM and EDX analyses of $\mathrm{Ag}$-xAl sessile drops:

1 . The edge of all sessile drops exhibited a thin reaction zone that included $\mathrm{Al}$ as well as $\mathrm{Ni}$ and $\mathrm{Fe}$ that were richer and poorer, respectively, than the nominal Kovar ${ }^{\mathrm{TM}}$ composition. The reaction zone topography transitioned from relatively smooth at that edge to a grain-like structure toward the sessile drop center.

2. The Ag-10Al was distinguished from the other two filler metals by having the additional mottled and spheroidal topographies, "D" and "E," respectively, at the sessile drop center.

3. Cracks were absent from all Ag$2 \mathrm{Al}$ reaction layers. However, such cracks were observed for all Ag-5Al and Ag-10Al sessile drops, regardless of brazing parameters.

4. The EDX analysis did not identify, qualitatively, significant variations of $\mathrm{Al}, \mathrm{Fe}, \mathrm{Ni}$, and Co contents in the reaction layers as a function of $\mathrm{Ag}-\mathrm{xAl}$ composition or brazing conditions.

\section{Analysis of the Sessile Drop Cross Sections}

Metallographic cross sections were made through the sessile drops to fur- 
ther understand the reaction layer microstructure. Electron probe microanalysis (EPMA) was used to determine, quantitatively, the reaction layer composition(s). The Ag-0Al filler metal wetted the $\operatorname{Kovar}^{\mathrm{TM}}$ base material only when brazed at $995^{\circ} \mathrm{C}\left(1823^{\circ} \mathrm{F}\right)$ for $20 \mathrm{~min}$. A contact angle of approximately 35 deg was measured at the edge of the sessile drop. Despite the satisfactory wetting performance, a discernable reaction layer was absent from the Ag-0Al/Kovar ${ }^{\mathrm{TM}}$ interface and no further analysis addressed this filler metal.

An SEM image is shown in Fig. 20A of the Ag-2Al sessile drop brazed at $965^{\circ} \mathrm{C}\left(1769^{\circ} \mathrm{F}\right)$ and $5 \mathrm{~min}$. The reaction layer extended approximately 10 $\mu \mathrm{m}$ from the edge of the filler metal, which corresponds to the surface view in Fig. 13. The layer became thicker toward the center, albeit the thickness varied along the interface - Fig. 20B. Cracks were absent from the layer.

The location of the EPMA trace is identified by the yellow line in Fig. 20B. Because the layer was only slightly thicker than the $\mathrm{x}$-ray sampling volume, elemental variations could not be deciphered within it. When the Fe, $\mathrm{Ni}$, and Co elemental concentrations were combined, a single, pseudo-binary composition was determined to be (Fe, $\mathrm{Ni}, \mathrm{Co})_{73 \pm 3} \mathrm{Al}_{27 \pm 3} \approx(\mathrm{Fe}, \mathrm{Ni}, \mathrm{Co})_{3} \mathrm{Al}$. The error range is derived from the standard deviation of concentrations measured in the three traces. This composition is similar to the high-Al phase, $(\mathrm{Fe}, \mathrm{Ni}, \mathrm{Co})_{2} \mathrm{Al}$, observed in the reaction layer between Kovar $^{\mathrm{TM}}$ and the $\mathrm{Ag}-\mathrm{Cu}-\mathrm{Zr}$ filler metal.

The Ag-2Al sessile drop was examined that was brazed at $965^{\circ} \mathrm{C}$

$\left(1769^{\circ} \mathrm{F}\right)$ and the longer brazing time of 20 min. An SEM photograph shows the layer in Fig. 21A. Cracks were not observed in the reaction layer. The EMPA trace was made across the reaction layer, which was sufficiently thick for the technique to detect compositional variations within it. One of three EPMA plots is shown in Fig. 21B. An $\mathrm{Al}$ gradient was confirmed within the Kovar ${ }^{\mathrm{TM}}$ base material adjacent to the reaction layer (left of the red arrow), which included an increasing $\mathrm{Fe}$ signal and decreasing $\mathrm{Ni}$ and Co signals (left to right). The broad $\mathrm{Al}$ peak between the red and cyan arrows marked the reaction layer. Across the

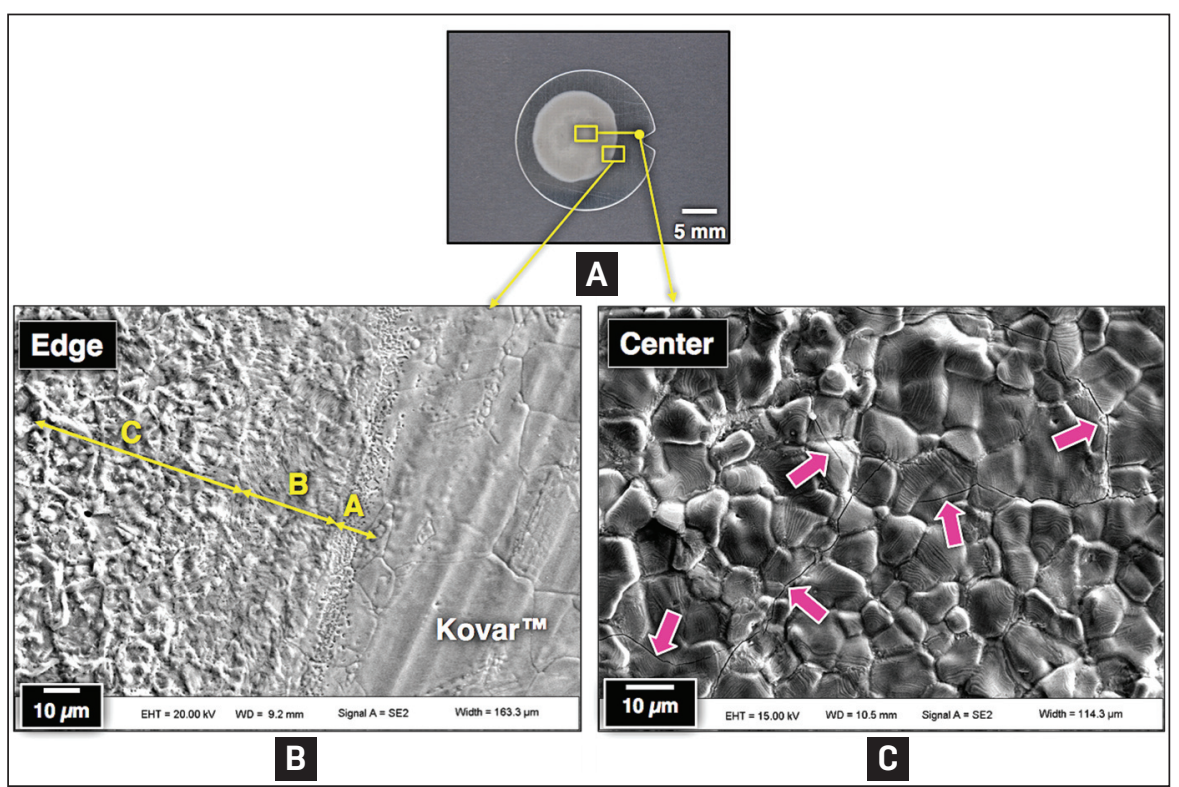

Fig. $17-A-$ Photograph shows the sessile drop created by the Ag-5Al filler metal brazed at $965^{\circ} \mathrm{C}\left(1769^{\circ} \mathrm{F}\right)$ and $20 \mathrm{~min}$. Yellow boxes indicate the edge and center locations that are shown by the SEM images $B$ and $C$, respectively. $B-S E M$ photograph identifies three reaction layer topographies indicated as "A," "B," and "C." C The reaction layer " $\mathrm{C}$ " exhibited cracks (magenta arrows).

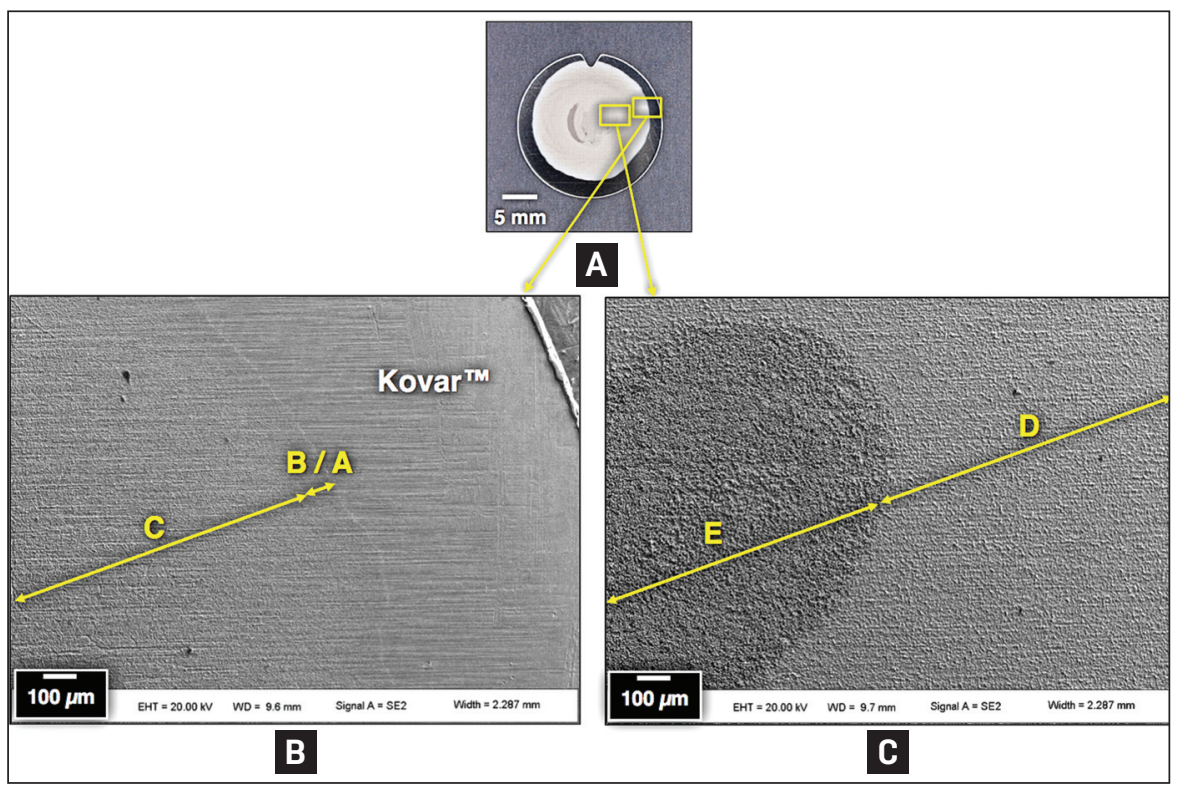

Fig. $18-A-$ Photograph of the sessile drop sample formed by the Ag-10Al filler metal under the brazing conditions of $965^{\circ} \mathrm{C}\left(1769^{\circ} \mathrm{F}\right)$ and $20 \mathrm{~min}$. The yellow boxes indicate the locations of the SEM photographs in $B$ and C. B - SEM image shows the edge of the sessile drop and topographies identified as " $\mathrm{B} / \mathrm{A}$ " and " $\mathrm{C}$." $\mathrm{C}$ - This SEM photograph indicates the " $D$ " and " $E$ " topographies observed toward the center of the sessile drop.

latter, the Co signal remained largely unchanged while the $\mathrm{Ni}$ and $\mathrm{Al}$ signals both showed peak concentration. The Fe trace decreased across the reaction layer. The trends differ from those associated with the $\mathrm{Al}$ gradient in the
Kovar $^{\mathrm{TM}}$ base material (left of the red arrow).

A peak in the Fe trace (red arrow) was observed between the Kovar ${ }^{\mathrm{TM}}$ base material and the reaction layer. Unfortunately, it was too narrow for 

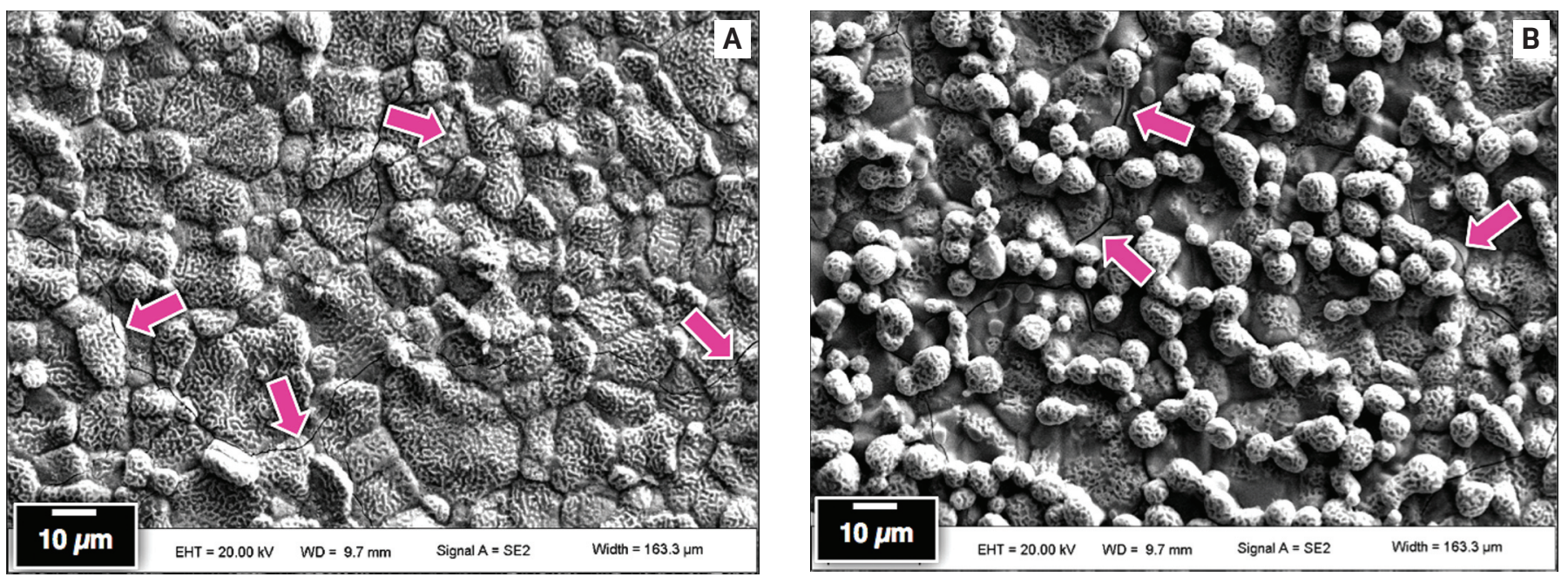

Fig. 19 - High-magnification SEM images show the $-A-$ " $D$ " and $B-$ " $E$ " topographies of the reaction layer that belong to the Ag-lOAl sessile drop [ $\left.965^{\circ} \mathrm{C}\left(1769^{\circ} \mathrm{F}\right), 20 \mathrm{~min}\right]$. The magenta arrows identify cracks in the reaction layers.
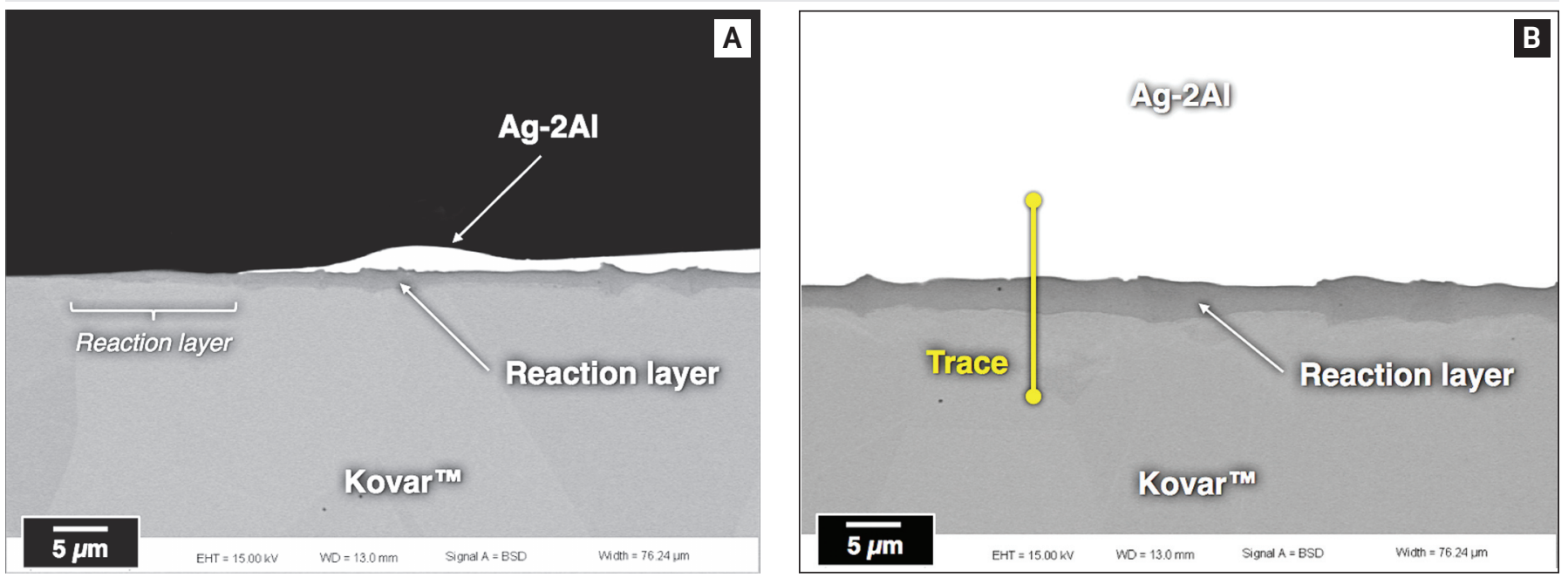

Fig. $20-A-S E M$ photograph shows a cross section at the edge of the Ag-2Al sessile drop. The process conditions were $965^{\circ} \mathrm{C}$ $\left(1769^{\circ} \mathrm{F}\right)$ and $5 \mathrm{~min} . \mathrm{B}-$ The SEM image shows the reaction layer toward the center of the sessile drop. The yellow line identifies the EPMA trace location.

the EPMA to determine a precise composition. Nickel, and to a lesser extent, Co, decreased when proceeding from the Kovar $^{\mathrm{TM}}$ base material toward the Fe peak. These trends suggest that $\mathrm{Ni}$ and Co were drawn from the Kovar ${ }^{\mathrm{TM}}$ to create the reaction layer, leaving the higher Fe concentration along with the $\mathrm{Al}$ gradient of $0-10$ at.- $\%$ in the nearby base material.

The broad EPMA reaction layer profile in Fig. 21B indicated the likelihood of multiple phases in the reaction layer. A methodology was developed to assign compositions to the two phases. Using Fig. 21B to illustrate the procedure, the orange arrow designates the location at which is determined the low-Al composition phase. That lo- cation is where the slope of the $\mathrm{Al}$ traces is at a minimum. The high-Al phase had its composition designated by the cyan arrow; it occurs at the $\mathrm{Al}$ peak. In the latter case, a second stipulation was that the Ag concentration be less than 0.1 at.-\% when there was remaining filler metal.

The above methodology determined the high-Al and low-Al phase compositions in Fig. 21B to be as follows:

- High-Al phase: (Fe, Ni, Co) ${ }_{67 \pm 1} \mathrm{Al}_{32 \pm 1}$ $\approx(\mathrm{Fe}, \mathrm{Ni}, \mathrm{Co})_{2} \mathrm{Al}$

- Low-Al phase: (Fe, Ni, Co $)_{74 \pm 1} \mathrm{Al}_{26 \pm 1}$ $\approx(\mathrm{Fe}, \mathrm{Ni}, \mathrm{Co})_{3} \mathrm{Al}$.

The additional brazing time, while not increasing the wetting and spread- ing activity of the sessile drop, did allow formation of the high-Al, dark phase. The latter phase's composition matched that of the high-Al phase observed at the $\mathrm{Ag}-\mathrm{Cu}-\mathrm{Zr} / \mathrm{Kovar}^{\mathrm{TM}}$ base material interface - Figs. 5-7. The low-Al phase had the same composition as the single reaction layer after 5 $\min$.

A significant thickness of Ag-2Al filler metal remained above the reaction layer - Fig. 21A. The EPMA measured its Al concentration to be $1.7-2.3$ at.-\% Al or $0.48-0.62$ wt-\%. Therefore, only approximately threequarters of the original $\mathrm{Al}$ content in the Ag-2Al filler metal participated in the reaction layer formation.

The cross sections were analyzed of 

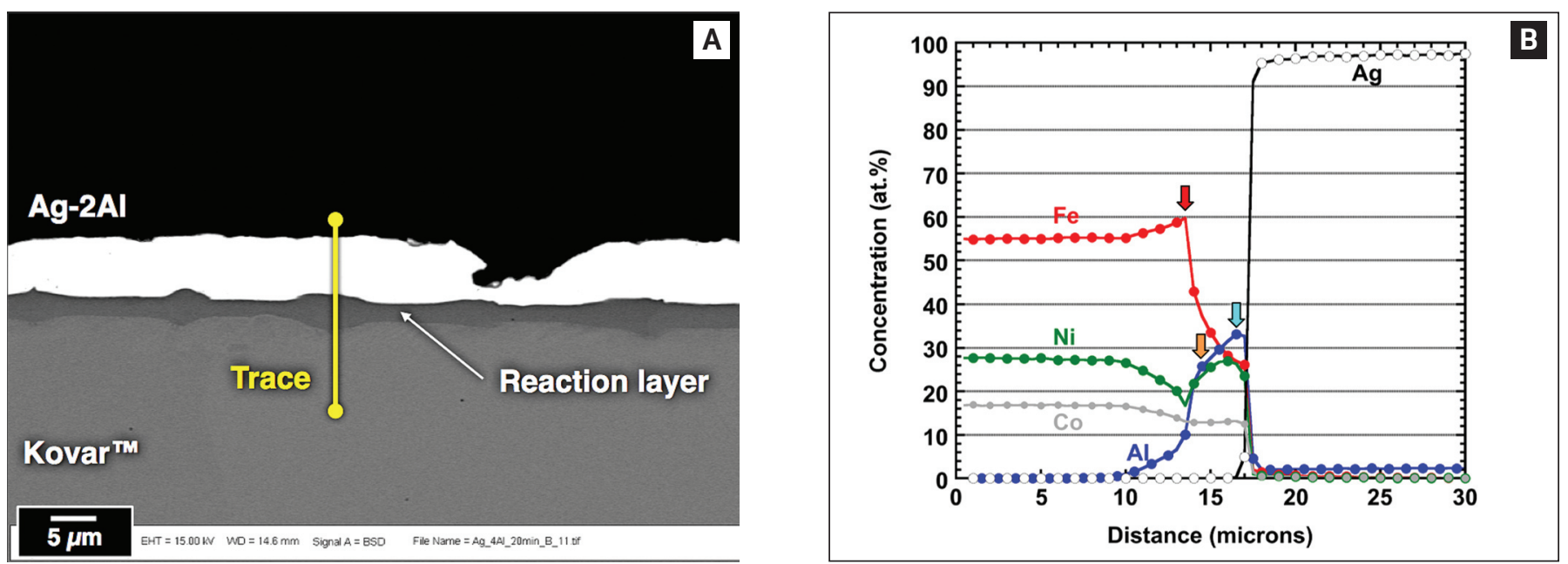

Fig. 21 - A - SEM photograph shows a cross section at the center of the Ag-2Al sessile drop. The process conditions were $965^{\circ} \mathrm{C}$ $\left(1769^{\circ} \mathrm{F}\right)$ and $20 \mathrm{~min}$. The yellow line marks the EPMA trace. B - The EPMA plot shows the $\mathrm{Fe}, \mathrm{Ni}, \mathrm{Co}, \mathrm{Al}$, and $\mathrm{Ag}$ signals. The red arrow marks the Fe peak; the orange and cyan arrows identify the measurement points of the low-Al and high-Al phases, respectively.
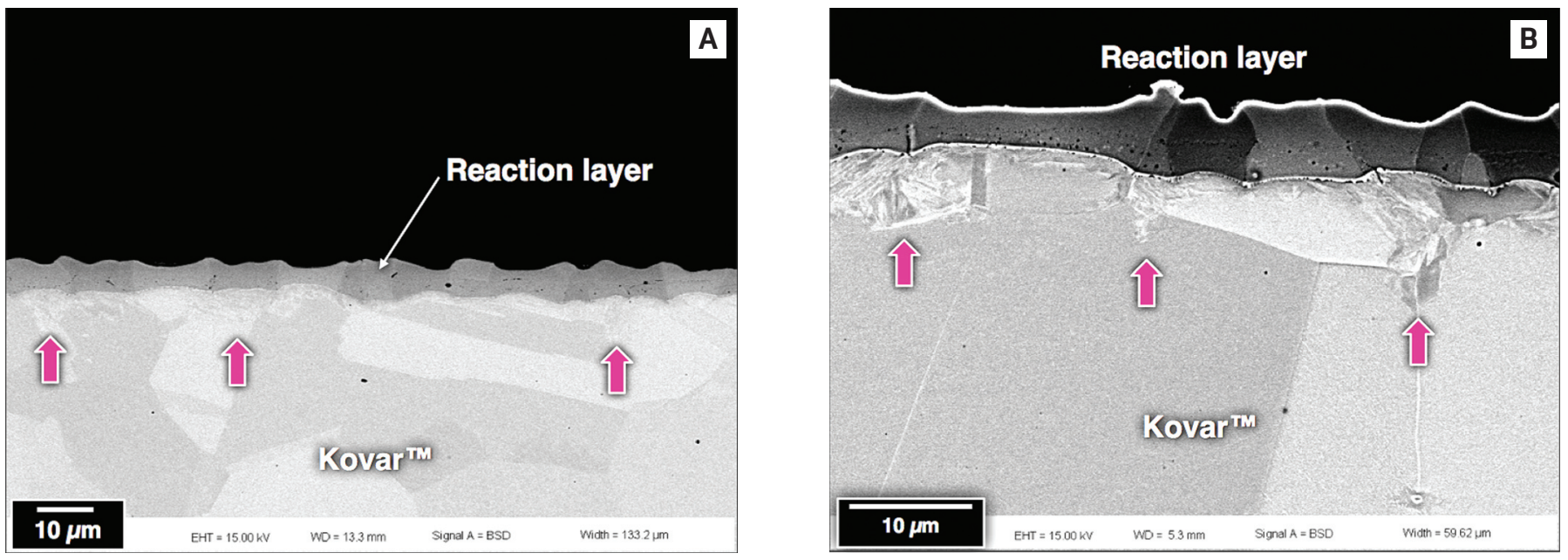

Fig. $22-\mathrm{A}$ - SEM image shows the reaction layer under the $\mathrm{Ag}-2 \mathrm{Al}$ sessile drop when brazed at $995^{\circ} \mathrm{C}\left(1823^{\circ} \mathrm{F}\right)$ for $20 \mathrm{~min}$. The magenta arrows indicate areas of recrystallization under the reaction layer. $B-B S E$ channeling contrast image highlights the recrystallization areas (magenta arrows).

the Ag-2Al sessile drops formed by brazing at $995^{\circ} \mathrm{C}\left(1823^{\circ} \mathrm{F}\right)$. The interface microstructures were similar between the 5- and 20-min brazing time; therefore, only the latter case will be discussed, here. The SEM photograph in Fig. 22A shows the reaction layer. Vertical grain boundaries are discernable in the image; the grain size corresponded to the surface grain-like structure in Fig. 16C. Cracks were not observed in the reaction layer.

The magenta arrows in Fig. 22A indicate areas of recrystallization in the Kovar $^{\mathrm{TM}}$ directly under the reaction layer. The recrystallization is further highlighted in Fig. 22B using the backscattered electron (BSE) channeling contrast technique (magenta ar- rows). The recrystallization phenomenon was also observed after $5 \mathrm{~min}$ at $995^{\circ} \mathrm{C}\left(1823^{\circ} \mathrm{C}\right)$. However, it occurred only intermittently and had very limited thicknesses. Closer scrutiny was given to previous SEM images of samples brazed at $965^{\circ} \mathrm{C}\left(1769^{\circ} \mathrm{F}\right)$. Those photographs confirmed the presence of recrystallization zones under the reaction layer. Those zones were also intermittent and relatively thin. Cracks were not observed in the recrystallization zones.

An analysis was performed to determine whether the recrystallization phenomenon was in response to a chemical stimulus or mechanical stress (dynamic recrystallization) introduced by the reaction layer. The absence of cracks in the reaction layer and recrystallization zone suggests that mechanical stress may have a lesser role. Therefore, the analysis turned to the compositional mechanism. Energydispersive $\mathrm{x}$-ray spectra were collected from the recrystallized region and in the far-field, Kovar $^{\mathrm{TM}}$ base material. Those measurements determined, albeit qualitatively, that there was an elevated Al concentration, as well as reduced concentrations of $\mathrm{Fe}$ and $\mathrm{Ni}$, in the recrystallized material when compared to the nominal Kovar ${ }^{\mathrm{TM}}$ composition.

An EPMA analysis was performed across the reaction layer, which included the recrystallization zone in the Ko$\operatorname{var}^{\mathrm{TM}}$ base material. The trace position 

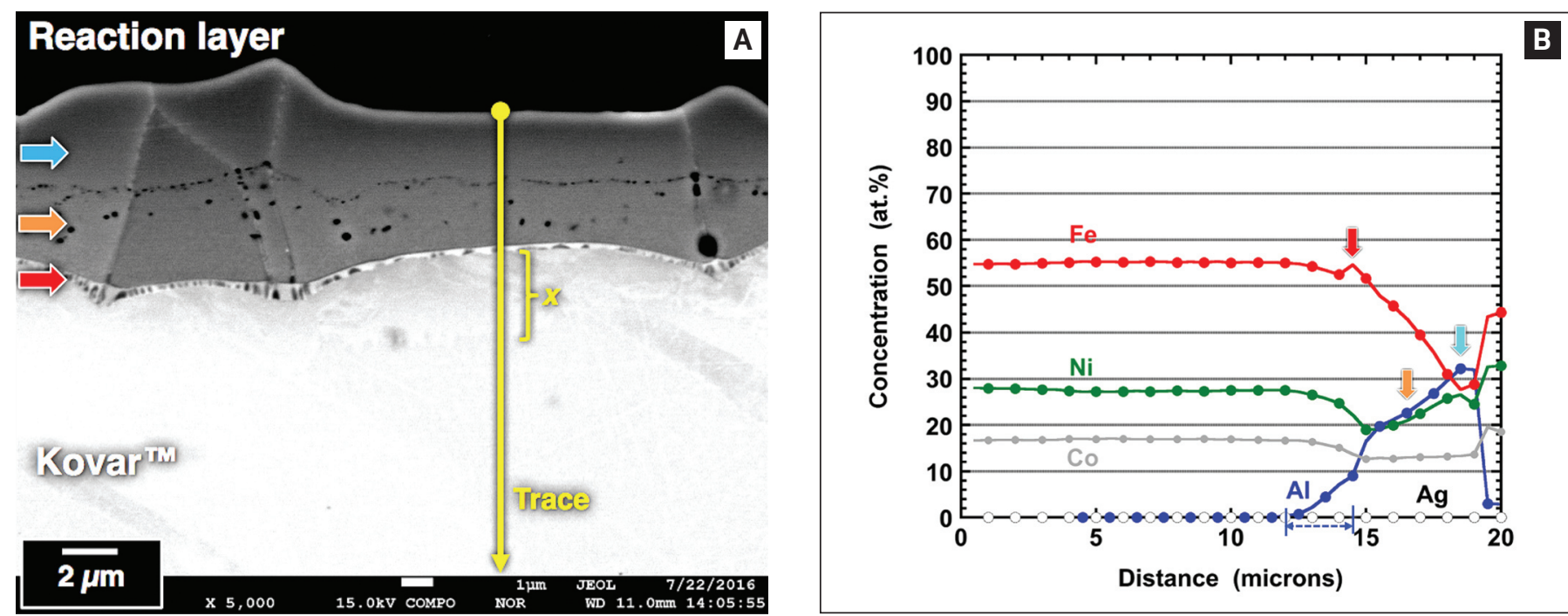

Fig. $23-\mathrm{A}-\mathrm{SEM}$ image shows the EPMA trace across the reaction layer of the $\mathrm{Ag}-2 \mathrm{Al}$ sample fabricated at $995^{\circ} \mathrm{C}\left(1823^{\circ} \mathrm{F}\right)$ and $20 \mathrm{~min}$. This trace crossed a recrystallization zone (" $x$ "). The blue, orange, and red arrows indicate the high-Al, low-Al, and Fe-rich layers, respectively. B - EPMA graph shows the $\mathrm{Fe}, \mathrm{Ni}, \mathrm{Co}, \mathrm{Al}$, and $\mathrm{Ag}$ traces across the reaction layer. The dashed blue arrow indicates the recrystallization zone.

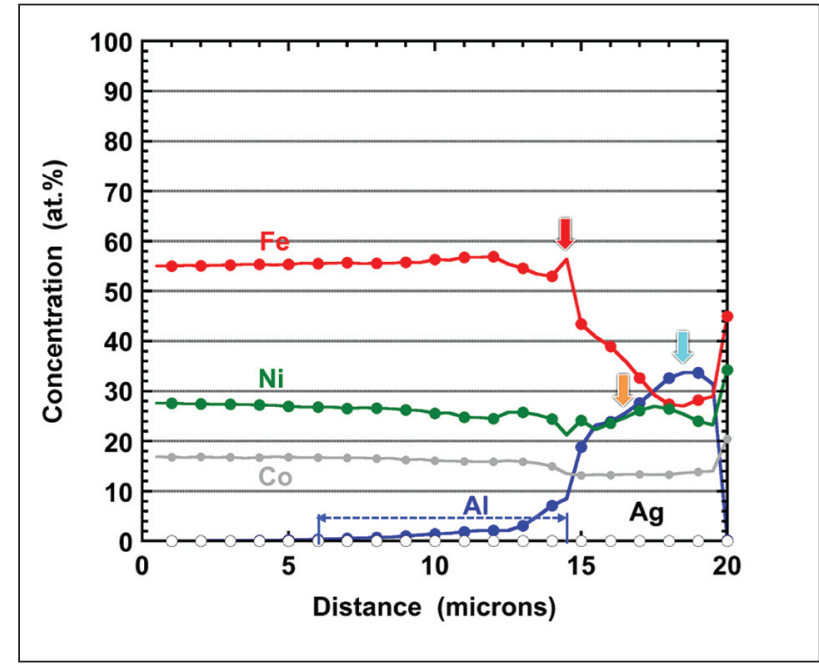

Fig. 24 - EPMA graph shows the $\mathrm{Fe}, \mathrm{Ni}, \mathrm{Co}, \mathrm{Al}$, and $\mathrm{Ag}$ traces across the reaction layer of the Ag-2Al sample formed at $995^{\circ} \mathrm{C}\left(1823^{\circ} \mathrm{F}\right)$ and $20 \mathrm{~min}$. The blue, orange, and red arrows indicate the high-Al, low-Al, and Fe-rich layers, repectively. The dashed blue arrow indicates the recrystallization zone.

is shown in Fig. 23A. The arrow at the bottom indicates the trace ended outside the field of view. The high-Al, low-Al, and high-Fe reaction layer phases are identified by the blue, orange, and red arrows, respectively. A series of dark spots formed a boundary between the high-Al and low-Al phases. Their dimensions were too small to have their composition(s) resolved by EPMA. Besides crossing the reaction layer, the trace also crossed the recrystallization zone (" $x$ ") and continued into the Kovar" base material. The elemental plot is shown in Fig. 23B. The colored arrows correspond to those in Fig. 23A. The high-Fe phase (red arrow) marks the end of the reaction layer and beginning of the recrystallization zone (" $\mathrm{x}$ "). That zone is approximately $3 \mu \mathrm{m}$ wide in Fig. 23A and is indicated by the blue, dashed arrow in Fig. 23B. An $\mathrm{Al}$ gradient was present, which ranged from 0 to 10 at.-\% in the recrystallization area and was accompanied by reduced $\mathrm{Fe}, \mathrm{Ni}$, and Co concentrations.

The role of $\mathrm{Al}$ in the Kovar ${ }^{\mathrm{TM}}$ recrystallization zone was further substantiated by performing the EPMA on a wider such zone of $\approx 8 \mu \mathrm{m}$ in the same sample. The corresponding EPMA plot is shown in Fig. 24. The dashed blue arrow indicates the presence of an $\mathrm{Al}$ gradient that extended farther into the Kovar $^{\mathrm{TM}}$ base material. The EPMA data in Figs. 23B and 24 provide evidence that the recrystallization was more likely to have been compositionally induced by $\mathrm{Al}$ diffusion into the Kovar $^{\mathrm{TM}}$ base material.

The EPMA data shown in Figs. 23B and 24 (plus a third trace) were used to determine the compositions of the high-Al and low-Al reaction layer phases - the blue and orange arrows, respectively, in Fig. 23A. Those compositions were

- High-Al phase: (Fe, Ni, Co) ${ }_{67 \pm 1} \mathrm{Al}_{32 \pm 2}$ $\approx(\mathrm{Fe}, \mathrm{Ni}, \mathrm{Co})_{2} \mathrm{Al}$

- Low-Al phase: (Fe, Ni, Co) ${ }_{76 \pm 3} \mathrm{Al}_{24 \pm 1}$ $\approx(\mathrm{Fe}, \mathrm{Ni}, \mathrm{Co})_{3} \mathrm{Al}$.

These compositions differed only slightly from the same phases measured for the $\mathrm{Ag}-2 \mathrm{Al}$ sample when brazed at $965^{\circ} \mathrm{C}\left(1769^{\circ} \mathrm{F}\right)$ for $20 \mathrm{~min}$. Lastly, the locations selected for EPMA did not have Ag-2Al filler metal remaining above the reaction layer.

The investigation turned to the Ag$5 \mathrm{Al}$ filler metal. The analysis began with the sessile drop brazed at $965^{\circ} \mathrm{C}$ $\left(1769^{\circ} \mathrm{F}\right)$ and $5 \mathrm{~min}$. Cracks were not present at the edge of the sessile drop where the reaction layer was thin. However, cracks were observed in the reaction layer as it grew thicker toward the center of the sessile drop. The cracks initiated in the high-Al phase and propagated into the low-Al phase below it, but not into the Kovar ${ }^{\mathrm{TM}}$ base. Small zones of recrystallization were observed in the Kovar ${ }^{\mathrm{TM}}$ base material 

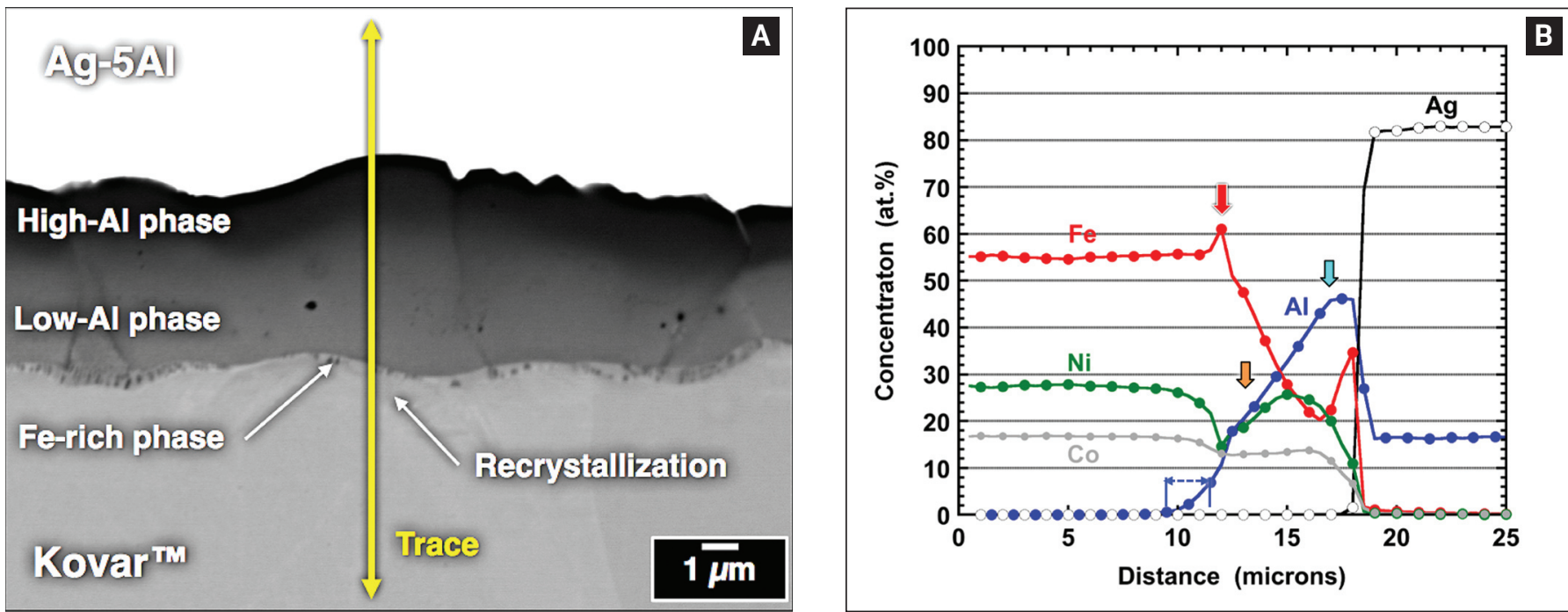

Fig. $25-\mathrm{A}-\mathrm{SEM}$ image shows the reaction layer and EPMA trace belonging to the $\mathrm{Ag}-5 \mathrm{Al}$ filler $\mathrm{metal}\left[965^{\circ} \mathrm{C}\left(1769^{\circ} \mathrm{F}\right)\right], 5 \mathrm{~min} . \mathrm{B}-$ EPMA graph shows the elemental distributions from the filler metal, across the reaction layer, and into the KovarTM base material. The blue, orange, and red arrows indicate the high-Al, low-Al, and Fe-rich layers, respectively. The dashed blue arrow identifies the recrystallization zone.
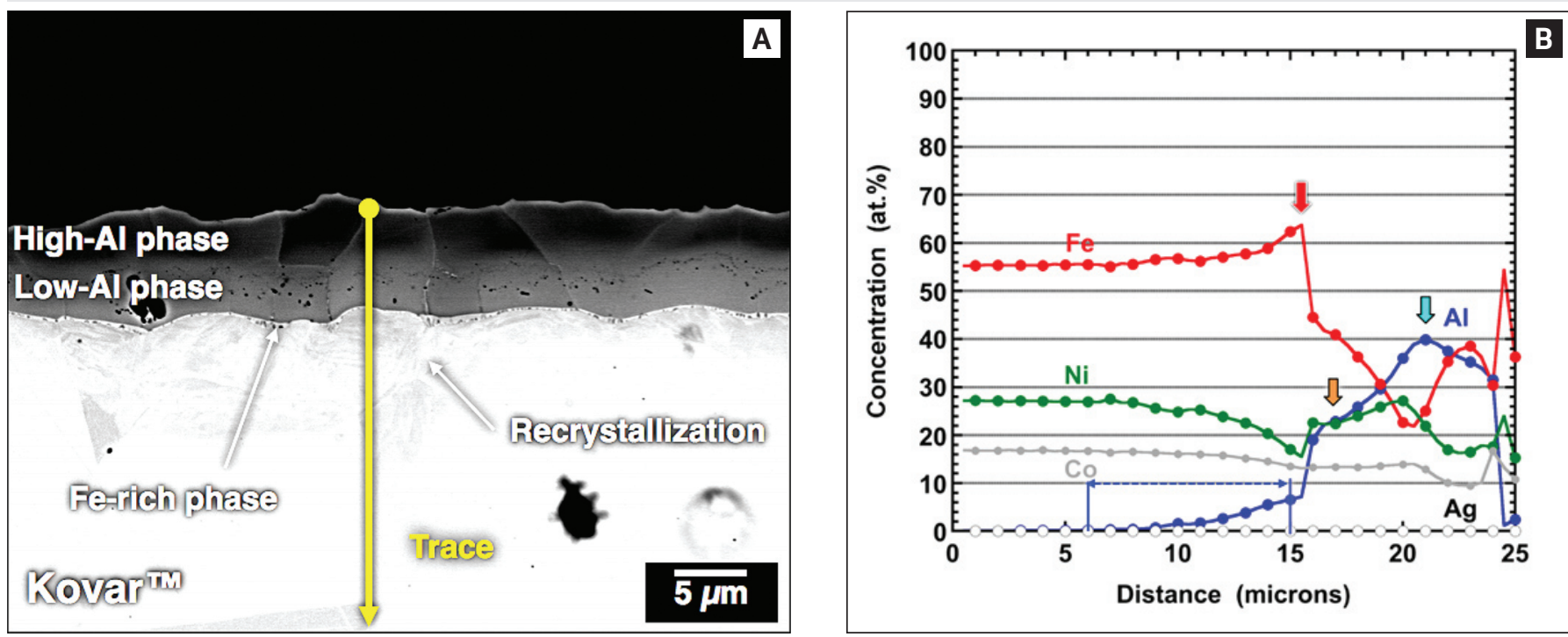

Fig 26. $-A-S E M$ image shows the reaction layer and EPMA trace location for the $\mathrm{Ag}-5 \mathrm{Al}$ sessile drop formed at $995^{\circ} \mathrm{C}\left(1823^{\circ} \mathrm{F}\right)$ and 20 min. B - EPMA plot shows the elemental distributions. The blue, orange, and red arrows indicate the high-Al, low-Al, and Fe-rich layers. The dshed blue arrow identifies the Al gradient characteristic of the recrystallization zone.

under the reaction layer.

The EPMA trace was performed across the reaction layer as shown in Fig. 25A; here, it crossed a very thin recrystallization zone $(1-2 \mu \mathrm{m})$. The arrow heads indicate the trace began, and ended, outside the field of view. The corresponding EPMA graph is shown in Fig. 25B. The recrystallization area is identified in Fig. 25B by the blue dashed arrow. Overall, the Fe, $\mathrm{Ni}, \mathrm{Co}$, and $\mathrm{Al}$ traces showed the same general trends as were observed with the Ag-2Al filler metal across the braz- ing conditions. The primary difference was the thicker reaction layer in Fig. $25 \mathrm{~B}(\mathrm{Ag}-5 \mathrm{Al}, \approx 8 \mu \mathrm{m})$ vs. that in Fig. 20B (Ag-2Al, $\approx 4 \mu \mathrm{m})$. A second difference was the consistent appearance of an Fe peak at the reaction layer/filler metal interface to the right of the cyan arrow. The Al signal remained elevated while the $\mathrm{Ni}$ and $\mathrm{Co}$ signals decreased rapidly to 11 and 6 at.-\%, respectively, under that Fe peak. The Fe peak region was too thin to obtain a precise composition.

The orange and cyan arrows in Fig.
25B identify the locations where the compositions were determined for the low- and high-Al phases, respectively. Those compositions are listed below:

- High-Al phase: (Fe, Ni, Co) ${ }_{55+1} \mathrm{Al}_{45 \pm 2}$ $\approx(\mathrm{Fe}, \mathrm{Ni}, \mathrm{Co})_{6} \mathrm{Al}_{5}$

- Low-Al phase: (Fe, Ni, Co) ${ }_{76 \pm 3} \mathrm{Al}_{24 \pm 1}$ $\approx(\mathrm{Fe}, \mathrm{Ni}, \mathrm{Co})_{3} \mathrm{Al}$

The low-Al phase had a composition that duplicated those measured for the same layer under the Ag-2Al filler metal. However, the high-Al 

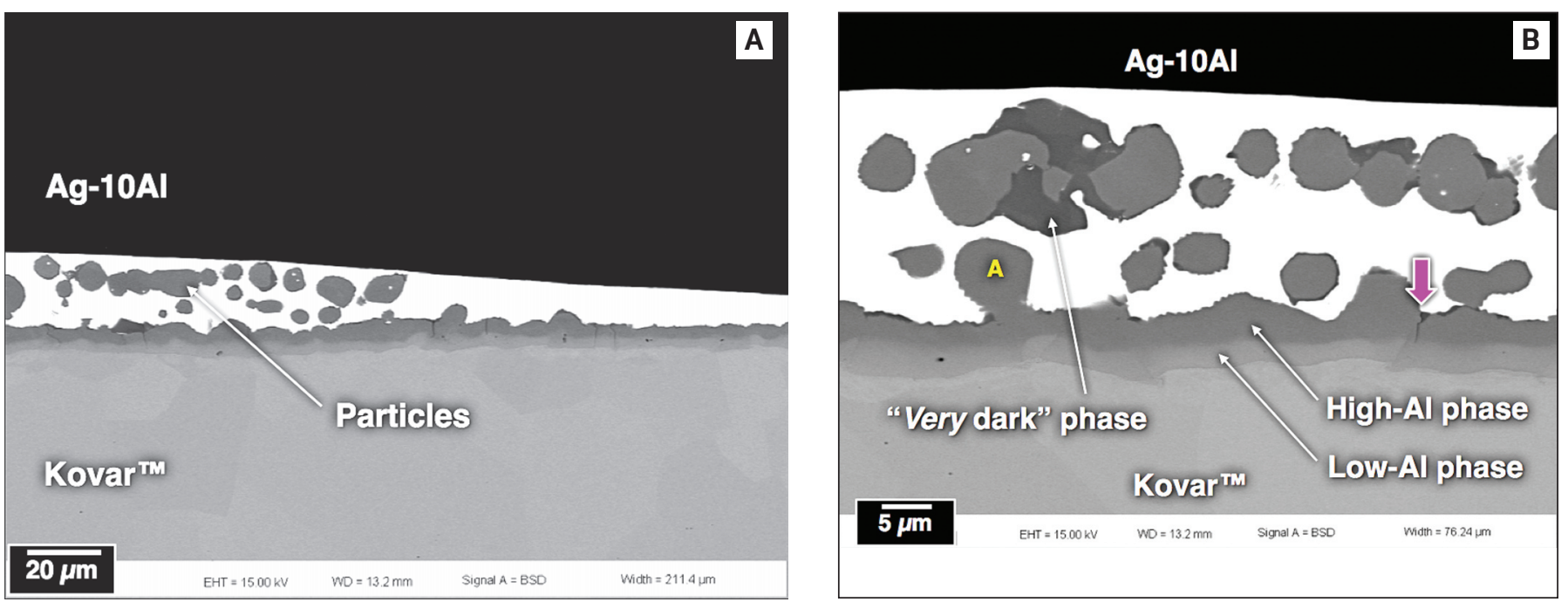

Fig. 27-A - SEM image shows the Ag-IOAl sessile drop near to the edge of the sessile drop. The brazing conditions were $965^{\circ} \mathrm{C}$ ( $\left(769^{\circ} \mathrm{F}\right.$ ) and $5 \mathrm{~min} . \mathrm{B}-\mathrm{SEM}$ image shows the sample microstructure at the sessile drop center. A "very dark" phase appears in the filler metal. The magenta arrow identifies a crack in the reaction layer. The particle "A" appears to have spalled from the reaction layer.

phase was considerably richer in $\mathrm{Al}$ than the reaction layers of those previous samples.

Sufficient Ag-5Al filler metal remained over the reaction layer for the EPMA to determine a retained $\mathrm{Al}$ concentration of 16-17 at.-\%, or 4.5-5.0 wt-\% - Fig. 25B. The absence of precipitates implies the $\mathrm{Al}$ was in solid solution. These data indicate little $\mathrm{Al}$ went toward development of the reaction layer.

The Ag-5Al samples, which were fabricated at $965^{\circ} \mathrm{C}\left(1769^{\circ} \mathrm{F}\right), 20 \mathrm{~min}$, and $995^{\circ} \mathrm{C}\left(1823^{\circ} \mathrm{F}\right), 5 \mathrm{~min}$, exhibited an interface microstructure similar to that in Fig. 25A. The EPMA was not performed on these samples.

The Ag-5Al sample is examined, which was brazed at the most severe conditions of $995^{\circ} \mathrm{C}\left(1823^{\circ} \mathrm{F}\right)$ and 20 $\min$. The reaction layer was $\approx 9 \mu \mathrm{m}$ thick, which is only slightly thicker than that formed at $965^{\circ} \mathrm{C}\left(1769^{\circ} \mathrm{F}\right)$ and 5 min. Crack development was observed in both the high-Al and low-Al phases of the reaction layer. The SEM image in Fig. 26A shows the reaction layer. Significant recrystallization activity occurred in the Kovar ${ }^{\mathrm{TM}}$ base material. The EPMA trace is shown in the image. The arrowhead indicates that the trace extended outside the bottom of the image. The corresponding elemental plot is shown in Fig. 26B. The substantial recrystallization zone is mapped by the dashed blue arrow in Fig. 26B. The red, orange, and cyan arrows identify the Fe- rich as well as low-Al and high-Al phases, respectively.

The compositions of the high-Al and low-Al phases are shown below.

- High-Al phase: (Fe, Ni, Co $)_{61 \pm 3} \mathrm{Al}_{39 \pm 1}$ $\approx(\mathrm{Fe}, \mathrm{Ni}, \mathrm{Co})_{3} \mathrm{Al}_{2}$

- Low-Al phase: $(\mathrm{Fe}, \mathrm{Ni}, \mathrm{Co})_{76 \pm 1} \mathrm{Al}_{24 \pm 1}$ $\approx(\mathrm{Fe}, \mathrm{Ni}, \mathrm{Co})_{3} \mathrm{Al}$

The composition of the low-Al phase remained unchanged from all previous analyses. The high-Al phase composition exhibited an increased $\mathrm{Al}$ content, which was similar to that observed at $965^{\circ} \mathrm{C}\left(1769^{\circ} \mathrm{F}\right)$ and $5 \mathrm{~min}$.

The EPMA trace showed further development of an Fe-rich layer near the reaction layer/filler metal interface. The layer was sufficiently thick to determine an approximate composition as $(\mathrm{Fe}, \mathrm{Ni}, \mathrm{Co})_{64 \pm 1} \mathrm{Al}_{36 \pm 1}$ based on the three traces. This composition is slightly lower in $\mathrm{Al}$ than the high-Al, $(\mathrm{Fe}, \mathrm{Ni}, \mathrm{Co})_{61 \pm 3} \mathrm{Al}_{39 \pm 1}$ phase (cyan arrow), despite it being closer to the filler metal. Also, the Fe peak was accompanied by minima in both the $\mathrm{Ni}$ and Co contents.

The analysis moved on to the Ag$10 \mathrm{Al}$ sessile drop cross sections, beginning with the brazing conditions of $965^{\circ} \mathrm{C}\left(1769^{\circ} \mathrm{F}\right)$ and $5 \mathrm{~min}$. The SEM photograph in Fig. 27A shows particles in the remaining filler metal. The particles, which became more numerous toward the center of the sessile drop as shown in Fig. 27B, had a gray tone like that of the high-Al phase observed at the interface. A "very dark" phase also appeared with the particles in the filler metal as well as intermittently along the reaction layer/filler metal interface. The darker gray tone implies a higher $\mathrm{Al}$ content. Short cracks (magenta arrow) were observed in the high-Al phase of the reaction layer. The EPMA first addressed the interface reaction layer phases and secondly, the particles in the filler metal.

Three EPMA traces, which targeted the interface reaction layer, began in the Ag-10Al filler metal, crossed that reaction layer and modest recrystallization zone, and ended in the Kovar ${ }^{\mathrm{TM}}$ base material - Fig. 28A. The arrow heads indicate the trace began and terminated outside the field of view of Fig. 28A. The corresponding EPMA plot is provided in Fig. 28B. The dashed blue arrow signifies the $\mathrm{Al}$ concentration gradient within the small recrystallization zone. The red arrow shows the location of the Fe-rich phase. The orange and cyan arrows identify the low-Al and high-Al phases in the reaction layer, respectively. The compositions of the latter two layers are listed below.

- High-Al phase: (Fe, Ni, Co $)_{48 \pm 1} \mathrm{Al}_{52 \pm 1}$ $\approx(\mathrm{Fe}, \mathrm{Ni}, \mathrm{Co}) \mathrm{Al}$

- Low-Al phase: (Fe, Ni, Co) $)_{74 \pm 2} \mathrm{Al}_{26 \pm 1}$ $\approx(\mathrm{Fe}, \mathrm{Ni}, \mathrm{Co})_{3} \mathrm{Al}$

The high-Al composition, (Fe, Ni, 

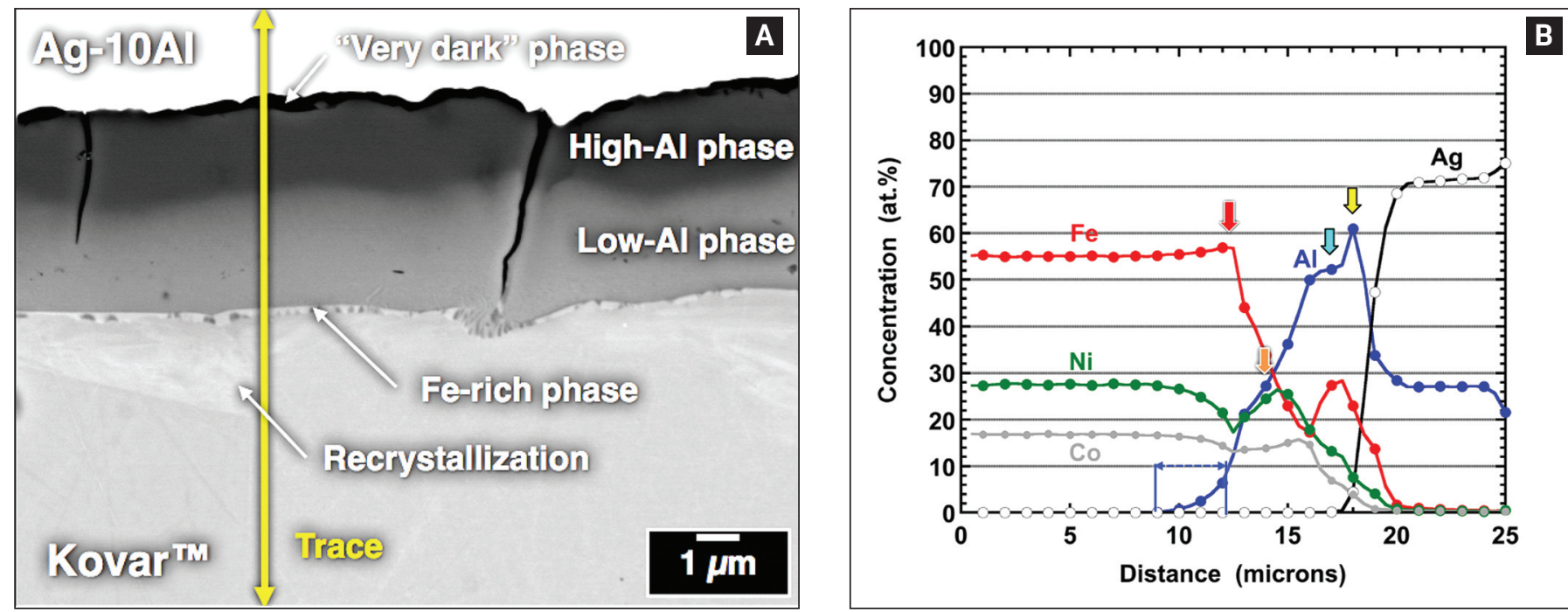

Fig. $28-A-S E M$ image shows the reaction layer and EPMA trace position for the Ag-10Al filler metal [ $\left.965^{\circ} \mathrm{C}\left(1769^{\circ} \mathrm{F}\right), 5 \mathrm{~min}\right] . \mathrm{B}-$ EPMA plot shows the elemental distributions. The blue, orange, and red arrows indicate the high-Al, low-Al, and Fe-rich layers, respectively. The yellow arrow indicates an Fe concentration peak near the interface. The dashed blue arrow identifies the Al gradient across the recrystallization zone.

Co)Al, experienced a further increase of $\mathrm{Al}$ content than the same layer that formed with the Ag-5Al alloy and the same brazing conditions. The composition of the low-Al phase remained unchanged from the EPMA traces corresponding to the $\mathrm{Ag}-5 \mathrm{Al}$ and $\mathrm{Ag}-2 \mathrm{Al}$ filler metals.

A yellow arrow in Fig. 28B identifies the very dark layer that formed at the reaction layer/filler metal interface noted in Fig. 28A. That layer exhibited a spike in the $\mathrm{Al}$ signal that was repeatable between the three traces. An approximation was made of the phase composition: $(\mathrm{Fe}, \mathrm{Ni}, \mathrm{Co})_{46.8 \pm 0.5} \mathrm{Al}_{3.2 \pm 0.3}$ $\approx(\mathrm{Fe}, \mathrm{Ni}, \mathrm{Co})_{7} \mathrm{Al}_{8}$. The error terms represent the repeatability of the composition determination. The composition is slightly higher in Al than the neighboring high-Al phase (cyan arrow).

The three traces also measured the $\mathrm{Al}$ content in the remaining filler metal - Fig. 28A. The $\mathrm{Al}$ concentrations were as follows: Trace $1,8.6 \pm 0.1 \mathrm{wt}-\%$ (27.0 \pm 0.2 at. $-\%)$; Trace 2, $8.5 \pm 0.2$ wt-\% (26.9 \pm 0.5 at. $-\%)$; and Trace $3,8.5 \pm 0.2$ wt-\% (26.8 \pm 0.4 at.-\%). These data indicate a relatively small amount of the $\mathrm{Al}$ content was used to form the reaction products (layers and particles). The AgAl binary alloy phase diagram shows an equivalent Al-8.5Ag composition would solidify with a microstructure comprised of the $\delta$ phase, $\mathrm{Ag}_{3} \mathrm{Al}_{2}$, together with the Ag-6Al solid-solution phase under equilibrium conditions (Ref. 7). These results imply that the presence of the reaction products perturbed that equilibrium, thereby allowing for development of the supersaturated, Ag-8.5Al solid solution and an absence of the $\mathrm{Ag}_{3} \mathrm{Al}_{2}$ phase.

The compositions of the particles were captured by four additional EPMA traces. The SEM photograph in Fig. 29A indicates the locations of traces \#1 and \#3 that are examined in the current analysis. Trace \#1 intercepted two particles labeled A and B; the EPMA graph is shown in Fig. 29B. The particle A composition was nearly identical to that of the high-Al phase in the reaction layer. Like the latter, particle A had the "very dark" phase at its edge that faced the filler metal and is indicated by the spike in the Al signal.

The particle B (Fig. 29B) exhibited compositional variations as first indicated by its gray tones in the Fig. 29A SEM image. Three compositions were analyzed and designated B-1, B-2, and B-3 in Fig. 29B; they are listed below:
- B-1: $(\mathrm{Fe}, \mathrm{Ni}, \mathrm{Co})_{29 \pm 1} \mathrm{Al}_{71 \pm 1} \approx(\mathrm{Fe}, \mathrm{Ni}$, Co) $\mathrm{Al}_{3}$
- B-2: $(\mathrm{Fe}, \mathrm{Ni}, \mathrm{Co})_{30 \pm 1} \mathrm{Al}_{70 \pm 2} \approx(\mathrm{Fe}, \mathrm{Ni}$, Co) ${ }_{3} \mathrm{Al}_{7}$
- B-3: (Fe, Ni, Co $)_{28 \pm 1} \mathrm{Al}_{72 \pm 1} \approx(\mathrm{Fe}, \mathrm{Ni}$, Co) $\mathrm{Al}_{3}$.

The two compositions B-1 and B-3 are identical. Although the B-2 composition is statistically the same as the B1 and B-3 cases, its lighter gray tone is caused by the slightly greater concen- tration of the (Fe, $\mathrm{Ni}, \mathrm{Co}$ ) group that was owed largely to the Fe content. The Ni and Co signals exhibited a slow gradual drop in concentration within the B-1 and B-2 fields, only to form a plateau in the B-3 composition. A small Al spike was also observed at the particle edge facing the filler metal.

The EPMA plot belonging to trace \#3 is shown in Fig. 29C. Particle C, which was located near the reaction layer, had a composition identical to that of the latter's high-Al phase. Particle D had a variable compositional profile across it that was unlike that of particle B in trace \#1. The SEM image (Fig. 29A) did not exhibit a discernable gray tone variation because the (Fe, $\mathrm{Ni}, \mathrm{Co}$ ) and $\mathrm{Al}$ concentrations were constant. Rather, the concentration variations occurred within the (Fe, $\mathrm{Ni}, \mathrm{Co}$ ) group. The $\mathrm{Fe}$ and Co concentrations exhibited a minimum in the particle center that was accompanied by a maximum in the Ni signal. Both particles $C$ and $D$ exhibited an $\mathrm{Al}$ spike on the filler metal side of their respective geometries.

Two mechanisms were hypothesized to have generated the particles. The first process required $\mathrm{Fe}, \mathrm{Ni}$, and Co components to dissolve into the molten filler metal from the Kovar ${ }^{\mathrm{TM}}$ base material, react with $\mathrm{Al}$ in the filler metal, and lastly either precipitate immediately in the molten filler metal or upon solidification. The dissolution mechanism appears to be unlikely. In the present study, the very small $\mathrm{Fe}$, 


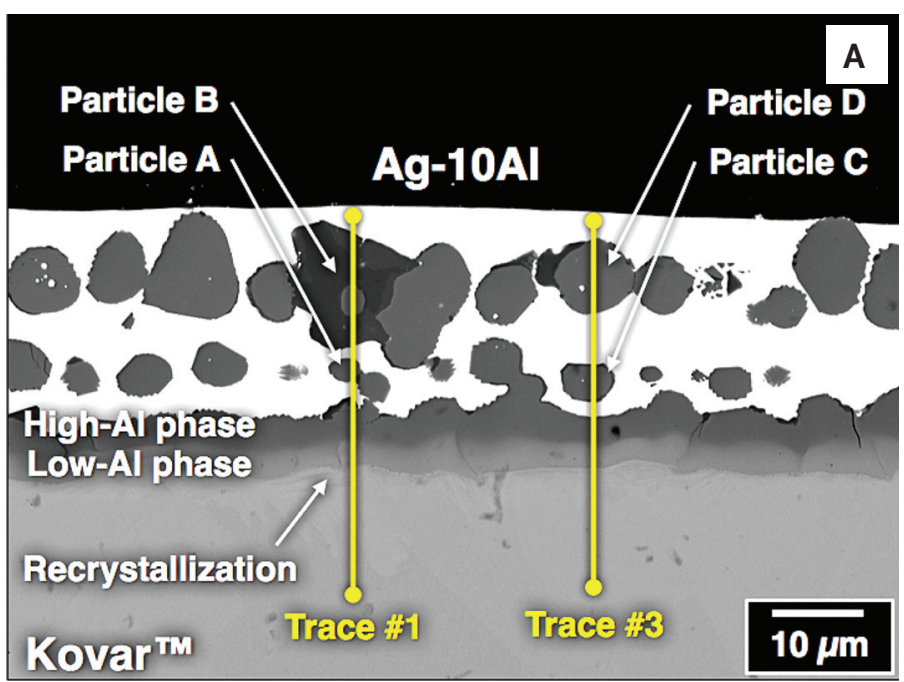

Fig. 29-A - SEM image shows the particles within, and EPMA trace positions \#1 and \#3 made across, the Ag-10Al filler metal and interface $\left[965^{\circ} \mathrm{C}\left(1769^{\circ} \mathrm{F}\right), 5 \mathrm{~min}\right]$. Particles are labelled $A, B$, $C$, and D. B, C-EPMA plots show the elemental distributions across traces \#1 and \#3, respectively. The corresponding structures are labeled in both cases.

$\mathrm{Ni}$, and Co concentrations were determined to be $0.27 \pm 0.06,0.12 \pm 0.03$, and $0.08 \pm 0.02$ wt-\%, respectively, which are at, or slightly below, the measurement error of this technique. An unpublished work by the present authors examined $\mathrm{Kovar}^{\mathrm{TM}} / 100 \mathrm{Ag} / \mathrm{Kovar}^{\mathrm{TM}}$ braze joints fabricated at $995^{\circ} \mathrm{C}$ and 5 min (Ref. 8). The EPMA of metallographic cross sections also detected low $\mathrm{Fe}(0.2-0.5 \mathrm{wt}-\%)$ as well as $\mathrm{Ni}$ and Co concentration (both 0.1-0.3 wt-\%) in the filler metal. These data did not indicate, explicitly, that $\mathrm{Fe}, \mathrm{Ni}$, and $\mathrm{Co}$ dissolved in the filler metal to a degree that, when combined with the $\mathrm{Al}$ content, would generate the particles. Of course, a possible scenario is that the $\mathrm{Al}$ addition to the filler metal enhanced the driving force and/or rate kinetics for $\mathrm{Fe}, \mathrm{Ni}$, and $\mathrm{Co}$ dissolution activity into a $\mathrm{Ag}$-xAl alloy.

The second mechanism begins with growth of the reaction layer at the $\mathrm{Ag}$ $10 \mathrm{Al} / \mathrm{Kovar}^{\mathrm{TM}}$ interface that forms the (Fe, $\mathrm{Ni}, \mathrm{Co})_{\mathrm{x}} \mathrm{Al}_{\mathrm{y}}$ phases. Then, localized areas of the outboard, high-Al reaction product grew faster than the surrounding layer and spalled off into the molten filler metal. The particles drifted to the center of the molten filler metal due to buoyancy effects. The densities of metal aluminides are in the range of $6-8$ $\mathrm{g} / \mathrm{cm}^{3}\left(375-500 \mathrm{lb} / \mathrm{ft}^{3}\right)$ while that of silver is $10.50 \mathrm{~g} / \mathrm{cm}^{3}\left(655 \mathrm{lb} / \mathrm{ft}^{3}\right)$ (Refs. 9 , 10). Once in the molten filler metal, the particle compositions changed into those recorded for particles $B$ and D in traces \#1 and \#3, respectively. Microstructural evidence supports this hypothesis. First, recall that particles $\mathrm{A}$ and $C$ in traces $\# 1$ and \#2, respectively,

which were closest to the reaction layer, had the same composition as the latter. Secondly, the SEM image in Fig. 27B captured one such particle "A" just prior to separating from the reaction layer.

An Al concentration of $8.3 \pm 0.1$ wt$\%$ was recorded in the remaining filler metal between the 45 - and $48-\mu \mathrm{m}$ positions of Fig. 29B. This value is slightly less than the 8.5-8.6 wt- $\%$ Al concentration measured near the interface reaction layer. The $\mathrm{Al}$ content did not exhibit a significant concentration gradient in the filler metal.

The next analysis examined the $\mathrm{Ag}$ $10 \mathrm{Al}$ sessile drop formed at $995^{\circ} \mathrm{C}$ $\left(1823^{\circ} \mathrm{F}\right)$ and $20 \mathrm{~min}$. The reaction layer structure is illustrated by the SEM image in Fig. 30A. Filler metal was lost completely from above the reaction layer. The high-Al and low-Al phases were present along with the Fe-rich layer. A significant recrystallization zone was present in the Kovar ${ }^{\mathrm{TM}}$ base material. A line of particles was ob- served within the low-Al phase, which resembled those observed in the low$\mathrm{Al}$ phase of the Ag-2Al alloy (Fig. 23A) when the filler metals were brazed under the same conditions. Although not present in this view, numerous vertical cracks developed in the reaction layer that propagated through both high-Al and low-Al phases.

The EPMA data are shown in Fig. $30 \mathrm{~B}$ that were obtained from the trace location shown in Fig. 30A. The recrystallization zone is identified by the dashed blue arrow. The Fe-rich phase is noted by the red arrow and was still too thin to obtain an accurate composition measurement. The compositions are listed below for the high-Al phase (cyan arrow) and low-Al phase (orange arrow):

- High-Al phase: (Fe, Ni, Co) $)_{57 \pm 2} \mathrm{Al}_{42 \pm 2}$ $\approx(\mathrm{Fe}, \mathrm{Ni}, \mathrm{Co})_{4} \mathrm{Al}_{3}$

- Low-Al phase: $(\mathrm{Fe}, \mathrm{Ni}, \mathrm{Co})_{75 \pm 2} \mathrm{Al}_{25 \pm 1}$ $\approx(\mathrm{Fe}, \mathrm{Ni}, \mathrm{Co})_{3} \mathrm{Al}$. 

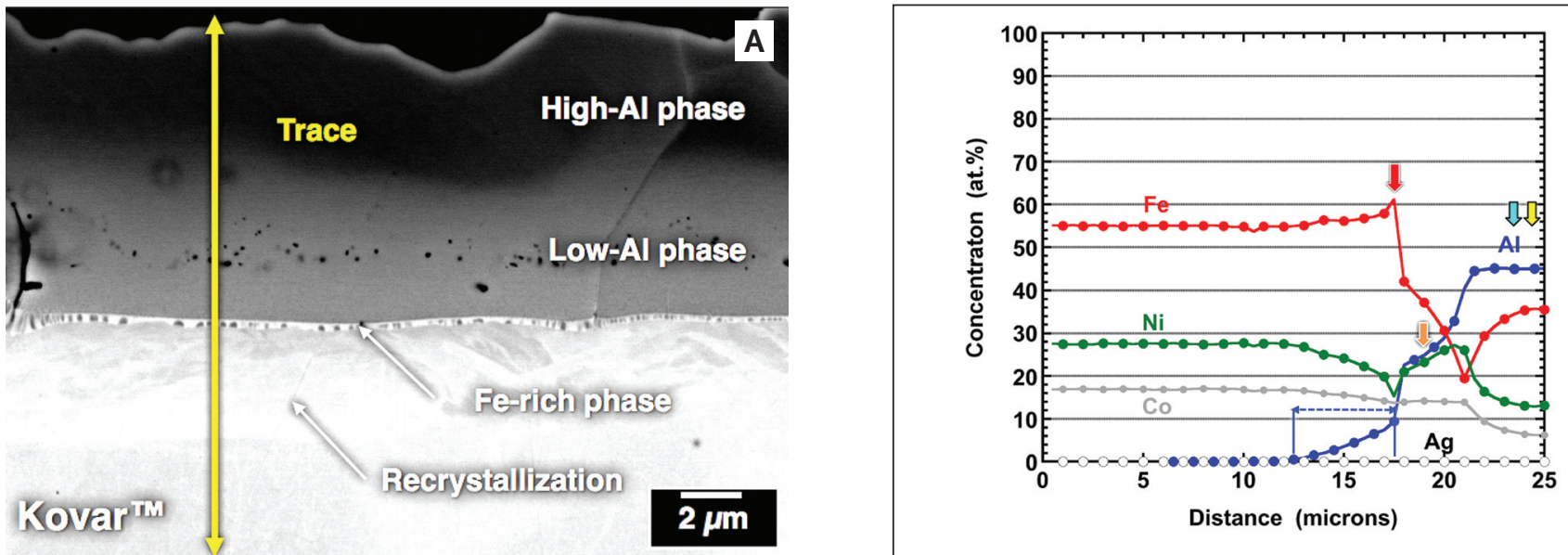

Fig. $30-A-S E M$ image shows the reaction layer that formed by the Ag-10Al filler metal when brazed at $995^{\circ} \mathrm{C}\left(1823^{\circ} \mathrm{F}\right)$ for 20 min. The location of the EPMA trace is noted in the image. B - EPMA plot shows the elemental distributions. The blue, orange, and red arrows indicate the high-Al, low-Al, and Fe-rich layers, respectively. The yellow arrow indicates an Fe concentration peak near the interface. The dashed blue arrow shows the Al gradient across the recrystallization zone.

The high-Al phase had a slightly reduced Al concentration than was observed under the less severe $965^{\circ} \mathrm{C}$ $\left(1769^{\circ} \mathrm{F}\right)$ and 5 -min brazing conditions. The low-Al phase had the same composition as in all previous samples.

A peak in the Fe signal was observed near the interface between the reaction layer and what would have been the $\mathrm{Ag}$ $10 \mathrm{Al}$ filler metal. The Fe maximum was compensated by minima in both the $\mathrm{Ni}$ and $\mathrm{Co}$ signals within the $(\mathrm{Fe}, \mathrm{Ni}, \mathrm{Co}$ ) grouping. This behavior is very similar to that observed for the $\mathrm{Ag}-10 \mathrm{Al}$ sessile drop brazed at $965^{\circ} \mathrm{C}\left(1769^{\circ} \mathrm{F}\right)$ for $5 \mathrm{~min}$ - Fig. 28B.

The EPMA data in Fig. 30B substantiate the more general trend observed throughout this study. Although specific concentrations were given to the high-Al and low-Al reaction layer phases, in fact, the Fe Ni, Co, and $\mathrm{Al}$ concentrations varied across each of them.

Such variations were repeatable and significant, particularly for the high-Al phase as a function of filler metal composition and the brazing process. Such composition changes are not unexpected, because interfaces do not necessarily represent the equilibrium structures that are reflected in binary or higher order, alloy phase diagrams.

\section{Discussion}

The images in Figs. 11 and 12 do not show the typical run-out lobes (e.g., Fig. 1) despite an abundance of $\mathrm{Al}$ in the filler metal. Nevertheless, Figs. 11 and

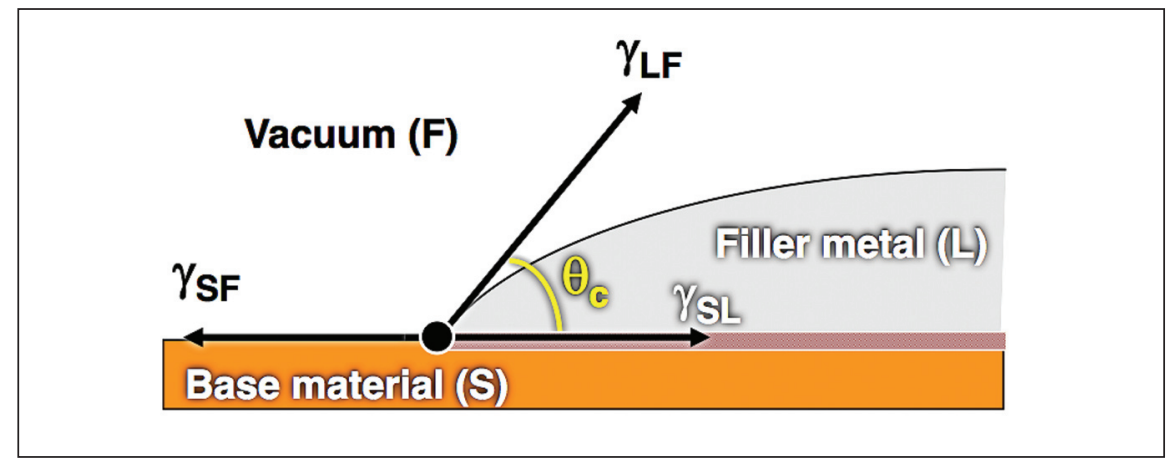

Fig. 31 - Schematic shows one-half of a sessile drop configuration and the balance of surface tensions that determine the contact angle, $\theta_{c}$, according to Young's equation.

12 illustrate that wetting and spreading increased with $\mathrm{Al}$ content. At first glance, the dependence on Al concentration suggests simply an $\mathrm{Al}$ availability factor. However, the EPMA data indicated that, when measurable, the remaining filler metals had an excess of $\mathrm{Al}$ after the brazing process at all three addition levels. Therefore, $\mathrm{Al}$ availability was not the controlling factor.

The analysis investigated secondary effects caused by the Al presence. The extent of wetting and spreading at equilibrium is predicted by Young's equation, which describes the balance of surface tensions at the edge of a sessile drop (Refs. 11, 12) - Fig. 31. Young's equation is written as:

$$
\gamma_{\mathrm{SF}}-\gamma_{\mathrm{SL}}=\gamma_{\mathrm{LF}} \cos \theta_{\mathrm{c}}
$$

where

- $\gamma_{\mathrm{SF}}$ is base material (S)/vacuum (F) in- terfacial tension;

- $\gamma_{\mathrm{SL}}$ is base material (S)/liquid filler metal (L) interfacial tension, which has the base material replaced with the reaction layer,

- $\gamma_{\mathrm{LF}}$ is liquid filler metal (L)/vacuum

(F) interfacial tension, and

- $\theta_{c}$ is the contact angle.

The smaller the value of $\theta_{c}$, greater is the wetting and spreading by the filler metal.

The trends of $\gamma_{\mathrm{SF}}, \gamma_{\mathrm{SL}}$, and $\gamma_{\mathrm{LF}}$ were analyzed as follows: The value of $\gamma_{\mathrm{SF}}$ is a constant for all Ag-xAl compositions and brazing parameters. The brazing conditions would not alter the surface oxide of the $\mathrm{Kovar}^{\mathrm{TM}}$ base material.

A semiquantitative analysis examined the role of the interfacial (surface) tension, $\gamma_{\mathrm{LF}}$ vs. Ag-xAl composition. The values of $\gamma_{\mathrm{LF}}$ are not known for the AgxAl binary system and their determina- 
Table 1-Aluminum Concentration of the Phase Contacting the Ag-XAl Filler Metal as a Function of Brazing Conditions

\begin{tabular}{|c|c|c|c|c|}
\hline Filler metal & $\begin{array}{c}965^{\circ} \mathrm{C}\left(1769^{\circ} \mathrm{F}\right) \\
5 \mathrm{~min}\end{array}$ & $\begin{array}{c}965^{\circ} \mathrm{C}\left(1769^{\circ} \mathrm{F}\right) \\
20 \mathrm{~min}\end{array}$ & $\begin{array}{c}995^{\circ} \mathrm{C}\left(1823^{\circ} \mathrm{F}\right), \\
5 \mathrm{~min}\end{array}$ & $\begin{array}{c}995^{\circ} \mathrm{C}\left(1823^{\circ} \mathrm{F}\right) \\
20 \mathrm{~min}\end{array}$ \\
\hline Ag-2Al & $\begin{array}{c}24 \text { at.- } \% \\
\text { (low-Al phase) }\end{array}$ & $\begin{array}{c}33 \text { at.-\% } \\
\text { (high-Al phase) }\end{array}$ & - & $\begin{array}{c}33 \text { at.-\% } \\
\text { (high-Al phase) }\end{array}$ \\
\hline $\mathrm{Ag}-5 \mathrm{Al}$ & $\begin{array}{c}45 \text { at.-\% } \\
\text { (high-Al phase) }\end{array}$ & - & - & $\begin{array}{c}40 \text { at.-\% } \\
\text { (high-Al phase) }\end{array}$ \\
\hline Ag-10Al & $\begin{array}{c}50 \text { at.-\% } \\
\text { (high-Al phase) }\end{array}$ & - & - & $\begin{array}{c}43 \text { at.- } \% \\
\text { (high-Al phase) }\end{array}$ \\
\hline
\end{tabular}

tion was beyond the scope of this study. Elemental Ag has values of $\gamma_{\mathrm{LF}}$ in the range of $958-967 \mathrm{mN} / \mathrm{m}$ for temperatures in the range of $965^{\circ}-995^{\circ} \mathrm{C}$ $\left(1769^{\circ}-1823^{\circ} \mathrm{F}\right)$ (Ref. 13). Molten $\mathrm{Al}$ has a surface tension of $1009 \mathrm{mN} / \mathrm{m}$ at $680^{\circ} \mathrm{C}\left(1256^{\circ} \mathrm{F}\right)$ under vacuum (Ref. 14$)$. Beside these values being relatively close to one another, the $\mathrm{Al}$ additions are less than $10 \mathrm{wt}-\%$, which would be expected to cause only small changes to the 100-Ag liquid surface tension (Ref. 15). So, $\gamma_{\mathrm{LF}}$ of the Ag-XAl alloys would be relatively insensitive to the present temperature range (Ref. 13). The conclusion was made that differences of $\gamma_{\mathrm{LF}}$ are predicted to be minor between the Ag-xAl compositions and, thus, unlikely to significantly influence the wetting and spreading activity.

The remaining parameter, $\gamma_{\mathrm{SL}}$, is determined by the reaction layer that is directly in contact with the molten Ag$\mathrm{xAl}$ filler metal. The $\mathrm{Al}$ concentration in the reaction layer increased with $\mathrm{Al}$ content in the filler metal, more so between the $\mathrm{Ag}-2 \mathrm{Al}$ and $\mathrm{Ag}-5 \mathrm{Al}$ reaction layers. This point is exemplified with data obtained from the brazing conditions of $995^{\circ} \mathrm{C}\left(1823^{\circ} \mathrm{F}\right)$ and $20 \mathrm{~min}$, which is shown below:

- Ag-2Al: $(\mathrm{Fe}, \mathrm{Ni}, \mathrm{Co})_{67 \pm 1} \mathrm{Al}_{32 \pm 2}$

$\approx(\mathrm{Fe}, \mathrm{Ni}, \mathrm{Co})_{2} \mathrm{Al}$

- Ag-5Al: (Fe, Ni, Co) ${ }_{61 \pm 3} \mathrm{Al}_{39 \pm 1}$

$\approx(\mathrm{Fe}, \mathrm{Ni}, \mathrm{Co})_{3} \mathrm{Al}_{2}$

- Ag-10Al: $(\mathrm{Fe}, \mathrm{Ni}, \mathrm{Co})_{57 \pm 2} \mathrm{Al}_{42 \pm 2}$

$\approx(\mathrm{Fe}, \mathrm{Ni}, \mathrm{Co})_{4} \mathrm{Al}_{3}$.

Unfortunately, the values of $\gamma_{\mathrm{SL}}$ are not available to calculate Equation 1. Under the above presumption that neither $\gamma_{\mathrm{SF}}$ or $\gamma_{\mathrm{LF}}$ changed significantly as a function of filler metal composition or brazing parameters, it was concluded that $\gamma_{\mathrm{SL}}$ controlled $\theta_{c}$ in Young's equation. An increase of the quantity of $\mathrm{Al}$ in the Ag-xAl filler metals led to an increased $\mathrm{Al}$ content of the high-Al phase, resulted in the increased wetting and spreading observed in Figs. 11 and 12. The resulting increase in wetting and spreading with higher $\mathrm{Al}$ content in the filler metal was interpreted as the actual run-out phenomenon. Based upon this scenario, the wetting and spreading behavior responsible for a run-out lobe (e.g., Fig. 1) is driven by a locally heightened, Al concentration in the molten filler metal.

The next step is to establish quantitative limits on the $\mathrm{Al}$ concentration responsible for run-out. The SEM analysis of the reaction layer surfaces identified similar topographies between the Ag$2 \mathrm{Al}$ and $\mathrm{Ag}-5 \mathrm{Al}$ compositions, regardless of the brazing parameters. However, the Ag-2Al and Ag-5Al filler metals differed by crack development: it was absent from all Ag-2Al samples, but present in the Ag-5Al samples. This observation was verified by the metallographic cross sections. Concurrently, there was a significant increase in $\mathrm{Al}$ content observed between the $\mathrm{Ag}-2 \mathrm{Al}$ and $\mathrm{Ag}-5 \mathrm{Al}$ reaction layers as demonstrated by the above bulleted compositions. The Ag-10Al sessile drops exhibited extensive wetting and spreading activity. The reaction layers exhibited cracking like those generated by the $\mathrm{Ag}$ $5 \mathrm{Al}$ filler metal (beside the additional mottling and nodules in Figs. 19A, B) as well as the similar, elevated $\mathrm{Al}$ content of the high-Al reaction layer. By considthereby causing a reduction of $\gamma_{\mathrm{SL}}$ that ering the Ag-10Al composition as already being in the run-out regime, the 5 wt- $\% \mathrm{Al}$ concentration is established as the lower limit of that phenomenon. Therefore, the transition between nominal wetting and spreading vs. run-out occurred in the range of $2-5 \mathrm{wt}-\% \mathrm{Al}$.

The run-out phenomenon is described by the following scenario: Runout is initiated by a localized spike of $2-5 \mathrm{wt}-\% \mathrm{Al}$ in the molten filler. The result is an increased $\mathrm{Al}$ concentration in the high- $\mathrm{Al},(\mathrm{Fe}, \mathrm{Ni}, \mathrm{Co})_{\mathrm{x}} \mathrm{Al}_{\mathrm{y}}$ phase. The latter condition leads to a decrease in $\gamma_{\mathrm{SL}}$ and thus, a decrease of the contact angle, $\theta_{c}$, causing an unstable wetting and spreading event that results in the run-out lobe.

These results obtained in the present study were compared to observations compiled in Ref. 1 that addressed run-out by the $\mathrm{Ag}-\mathrm{Cu}-\mathrm{Zr}$ filler metal. At locations where run-out was absent, cracks were also not observed in the reaction layer. The reaction layer composition was $(\mathrm{Fe}, \mathrm{Ni}, \mathrm{Co})_{2} \mathrm{Al}\left[982^{\circ} \mathrm{C}\right.$ $\left(1800^{\circ} \mathrm{F}\right) \approx 15 \mathrm{~min}, 600$ torr], which is very similar to that of the low-Al phase at the interface with the Ag-2Al alloy. Unfortunately, a similar analysis was not available of the reaction layer under the $\mathrm{Ag}-\mathrm{Cu}-\mathrm{Zr}$ run-out lobe. Nevertheless, this comparison suggests that the $\mathrm{Ag}-\mathrm{xAl}$ data correlate with the run-out behavior observed by the Ag$\mathrm{Cu}-\mathrm{Zr}$ filler metal.

Qualitative observations - including a comparison between Figs. 11 and 12 - indicated the degree of wetting and spreading was not strongly sensitive to brazing time and only slightly so with brazing temperature. The EPMA data were analyzed to determine if this trend correlated with an unchanging reaction layer composition. The $\mathrm{Al}$ concentrations are listed in Table 1 as a function of the brazing parameters for each Ag-xAl composition. The Ag-2Al alloy experienced a modest increase from 24 to 33 at.- $\% \mathrm{Al}$ in the reaction layer when going from 5 to $20 \mathrm{~min}$ at $965^{\circ} \mathrm{C}\left(1769^{\circ} \mathrm{F}\right)$. The corresponding sessile drops did not show a significant difference in wetting and spreading. The Al concentration remained unchanged between $965^{\circ}$ and $995^{\circ} \mathrm{C}\left(1769^{\circ}\right.$ and $\left.1823^{\circ} \mathrm{F}\right)$ for the 20-min brazing time, which correlated to an unchanged spreading activity between the sessile drops.

The Ag-5Al and Ag-10Al filler met- 
als caused significantly higher Al contents in the reaction layer phases, which were accompanied by the greater wetting and spreading performances. The insensitivity of wetting and spreading by the Ag-5Al and Ag-10Al alloys to the brazing conditions correlated with relatively small changes in the $\mathrm{Al}$ concentration between their respective high-Al reaction layers. In fact, the $\mathrm{Al}$ content decreased due to the Fe-peak near the reaction layer/filler metal interface. This analysis lends further evidence that wetting and spreading behavior as a whole, and the run-out instability in particular, were controlled expressly by the $\mathrm{Al}$ content of the reaction layer phase adjacent to the filler metal.

The Ag-xAl filler metal was susceptible to evaporation under the highvacuum brazing conditions. The degree of evaporation increased with brazing time and temperature; it also increased with increasing $\mathrm{Al}$ content. The latter was likely caused by a depression of the solidus temperature. Nevertheless, the reaction layer topographies and chemistries were not sensitive to filler metal evaporation because the interface reaction occurred too rapidly to be impacted by it.

The background discussion highlighted the importance of braze joint geometry on run-out behavior. The present study used only the sessile drop configuration. By combining the sessile drop data with observations from Ref. 1, an accentuated run-out behavior would be predicted for the gap configuration. The gap geometry eliminates the free surface of the filler metal. The $\gamma_{\mathrm{LF}}$ in Fig. 31 is replaced with the $\operatorname{Kovar}^{\mathrm{TM}}$ base material $\left(\gamma_{\mathrm{SL}}\right)$. The second Kovar $^{\mathrm{TM}}$ surface would provide an added driving force for run-out under a locally elevated Al concentration. This hypothesis is examined further in the Part 2 report.

Lastly, a long-term objective of this study is to use these data to develop potential mitigation strategies against run-out. Although details are pending, clearly the present study underscores the need to reduce the quantity of Al reaching the filler met$\mathrm{al} / \operatorname{Kovar}^{\mathrm{TM}}$ base material interface.

\section{Conclusions}

1. The run-out phenomenon has been observed in active braze joints made between alumina ceramic and Ko$\mathrm{var}^{\mathrm{TM}}$ base material using the filler metal, 97Ag-1Cu-2Zr (wt-\%). Run-out can be responsible for a significant yield loss at production. A study was undertaken to understand the fundamental principles behind run-out by examining the interface reaction between $\mathrm{Ag}$-xAl filler metals ( $\mathrm{x}=2,5$, and $10 \mathrm{wt}-\%)$ and Kovar $^{\mathrm{TM}}$ base material.

2. Wetting and spreading increased with $\mathrm{Al}$ content $(\mathrm{x})$ of the Ag-xAl filler metal, but was largely insensitive to the brazing process parameters.

3. Increasing the Al concentration of the filler metal raised the $\mathrm{Al}$ content of the $(\mathrm{Fe}, \mathrm{Ni}, \mathrm{Co})_{\mathrm{x}} \mathrm{Al}_{\mathrm{y}}$ reaction layer. This trend was also not particularly sensitive to brazing conditions.

4. The correlation was developed between wetting and spreading, $\mathrm{Al}$ concentration of the Ag-xAl alloy, and $\mathrm{Al}$ content in the reaction layer, which predicted that a run-out event would occur when the filler metal has a locally elevated $\mathrm{Al}$ concentration that exceeds $2-5 \mathrm{wt}-\%$.

5. Several mitigation strategies were derived from this study as potential solutions to the run-out defect, and will be investigated in future studies.

\section{Acknowledgments}

The authors wish to thank Lisa Deibler for her thorough review of the manuscript and Paul Kotula for the spectral analysis. Sandia National Laboratories is a multimission laboratory managed and operated by National Technology and Engineering Solutions of Sandia LLC, a wholly owned subsidiary of Honeywell International Inc. for the U.S. Department of Energy's National Nuclear Security Administration under contract DE-NA0003525.

\section{References}

1. Vianco, P. T., Walker, C. A., De Smet, D., Kilgo, A. C., Mckenzie, B. M., Kotula, P.
M., and Grant, R. L. 2015. Understanding the run-out behavior of a Ag-Cu-Zr braze alloy when used to join alumina to an Fe-NiCo alloy. Proc. $6^{\text {th }}$ International Brazing and Soldering Conference. Eds. R. Gourley and C. Walker, CD-ROM. Miami, Fla.: American Welding Society.

2. $\operatorname{Kovar}^{\mathrm{TM}}$ is a registered trademark of Carpenter Technologies, Reading, Pa.

3. ASTM F19-11, Standard Test Method for Tension and Vacuum Testing Metallized Ceramic Seals. 2011. ASTM, West Conshohocken, $\mathrm{Pa}$.

4. Kubaschewski, O., and Evans, E. 1956. Metallurgical Thermochemistry: $2^{\text {nd }}$ Edition. New York, N.Y.: Wiley and Sons. pp. 331-338.

5. Porter, W., and Maziasz, P. 1993. Thermal expansion data on several ironand nickel-aluminide alloys. Scripta Metall. 29: 1043-1048.

6. Harner, L. 1994. The use of Fe-29Ni17Co alloy in the electronics industry in Low Thermal Expansion Alloys and Compositions. Eds. J. Stephens and D. Frear. Warrendale, Pa.: TMS. pp. 3-16.

7. Binary Alloy Phase Diagrams: Volume 1. 1986. Ed. by T. Massalski. Materials Park, Ohio: ASM International. pp. 3, 4.

8. Vianco, P., Walker, C., Kilgo, A., and Grant, R. Unpublished data.

9. Deevi, S., and Sikka, V. 1995. Nickel and iron aluminides: An overview on properties, processing, and applications. Intermetallics 4: 357-375.

10. Handbook of Chemistry and Physics. $5^{\text {th }}$ edition. 1976. Cleveland, Ohio: CRC. B-33.

11. Young, T. 1805. An essay on the cohesion of fluids. Trans. R. Soc. Lond. 95: 65-87.

12. de Gennes, P. 1985. Wetting: Statics and dynamics. Rev. Mod. Phys. 57: 827-863.

13. Ozawa, S., Morohoshi, K., Hibiya, T., and Fukuyama, H. 2010. Influence of oxygen partial pressure on surface tension of molten silver. J. Appl. Phys. 107: 014910.

14. Anson, J., Drew, R., and Gruzleski, J. 1999. The surface tension of molten aluminum and $\mathrm{Al}-\mathrm{Si}-\mathrm{Mg}$ alloy under vacuum and hydrogen atmospheres. Metall. and Mater. Trans. B. 30B: 1027-1032.

15. Murr, L. 1975. Interfacial Phenomena in Metals and Alloys. Reading, Mass.: Addison-Wesley. pp. 101-106. 